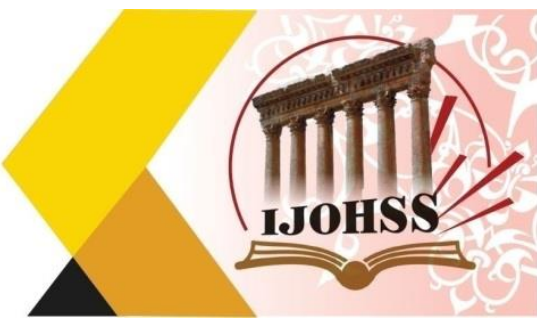

\title{
الوعي التاريخي لاى طلبة قسم التاريخ في جامعة كربلاء
}

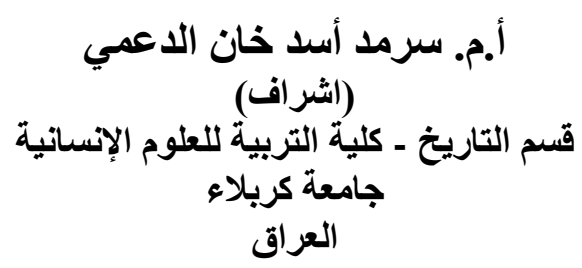

\author{
بان ذياب خضير فارس \\ (الباحثة) \\ قسم التاريخ ـ كلية التربية للعلوم الإنسانية \\ جامعة كربلاء \\ العراق العزي

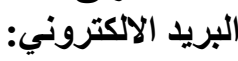 \\ ban.th@uokerbala.edu.iq
}

الملخص

يهدف البحث الحالي إلى التعرف على مستوى الوعي التاريخي، لدى طلبة قسم التاريخ جامعة كربلاء حسب متغيري(الجنس-المرحلة)؛ ومن اجل تحقيق هدف البحث فقد عمدت الباحثة إلى بناء اداة البحث بعد الاطلاع على مجمو عة كبيرة من الادبيات و الدراسات السابقة و كل ما له علاقة بموضوع البحث الحالي، أذ تم بناء اداة للبحث وهي (استبانة) تكونت من (3) مجالات و بواقع ( 38) فقرة نم استخر اج الصدق الظاهري لها بعرضها

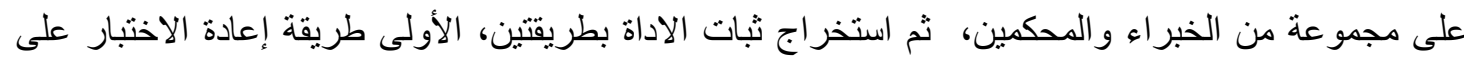
عينة عشو ائية عددها(50)طالب وطالبة، أذ بلغ معامل الثبات (86،0) بعد التصحيح ،و الثانية معادلة ألفا كرونباخ للاتساق الداخلي ولاستخر اج الثبات بهذه الطريقة تم تطبيق معادلة الفاكرونباخ على استجابات عينة التحليل الاحصائي التي بلغت (200) طالب وطالبة، وبعد تطبيق المعادلة بلغ معامل الثبات (0,82). طالب وطالبة من قسم التاريخ في كلية التربية للعلوم الإنسانية ، وبعد تحليل نتائج البحث احصائيا توصلت الباحثة إلى نتائج كان

- ان عينة البحث يمتلكون وعي تاريخي بمستوى عالي.

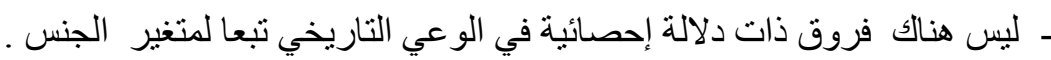
ـ ان الوعي التاريخي يزداد لدى الطلبة بتقدم المرحلة الدر اسية. الكلمات المفتاحية: الوعي التاريخي، طلبة قسم التاريخ، جامعة كربلاء. 


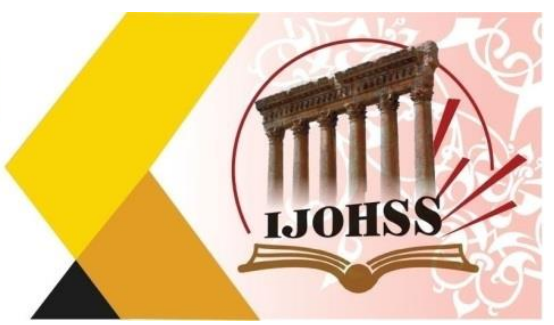

\title{
Historical Awareness among Students of the History Department at the University of Karbala
}

\author{
Ban Dhiab Khudair Faris \\ (researcher) \\ History Department - College of \\ Education for Human Sciences \\ Karbala University \\ Iraq \\ Email: ban.th@uokerbala.edu.iq
}

\author{
Asssist.Prof. Sarmad Asad Khan Al-Daami \\ (Supervisor) \\ History Department - College of Education \\ for Human Sciences \\ Karbala University \\ Iraq
}

\begin{abstract}
The current research aims to identify the level of historical awareness among the students of the History Department at the University of Karbala according to the two variables (sex-stage); In order to achieve the goal of the research, the researcher built a research tool after reviewing a large group of literature and previous studies and everything related to the topic of the current research. A paragraph for which the apparent validity was extracted by presenting it to a group of experts and arbitrators, and then extracting the stability of the tool in two ways, the first is the method of re-testing on a random sample of (50) male and female students, as the stability coefficient reached (0.86) after correction, and the second is the alpha-Cronbach equation. For internal consistency and to extract stability in this way, the Facronbach equation was applied to the responses of the statistical analysis sample, which amounted to (200) male and female students, and after applying the equation, the reliability coefficient reached (0.82). A male and female student from the Department of History at the College of Education for Human Sciences, and after analyzing the results of the research statistically, the researcher reached the following results: research statistically, the researcher reached.

the following results:

-The research sample possesses a high level of historical awareness.

- There are no statistically significant differences in historical awareness according to the gender variable

-.The historical awareness of students increases with the progress of the school stage
\end{abstract}

Keywords: Historical Awareness, Students of the History Department, University of Karbala. 


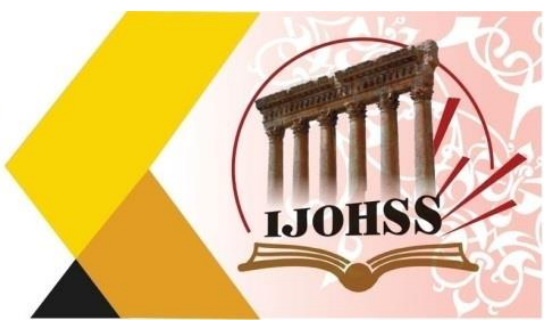

\section{الفصل الأول/ التعريف بالبحث}

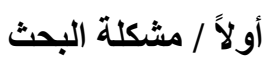

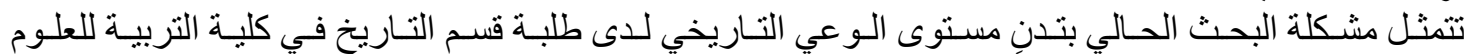

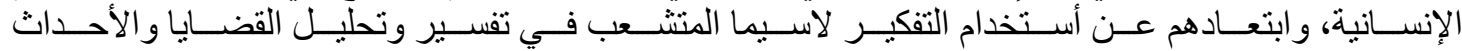

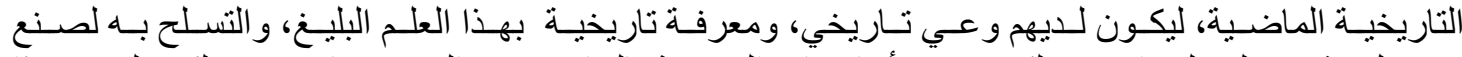

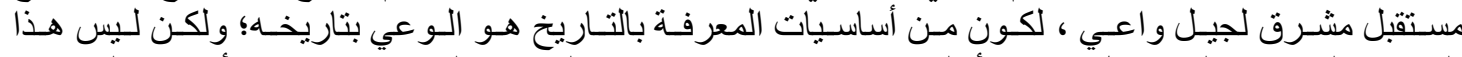

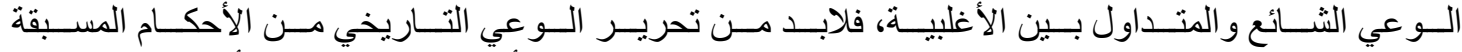

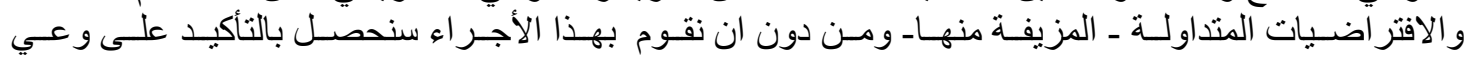

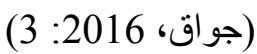

زائف، ولا يخدم غير الأهداف الأيديولوجية.

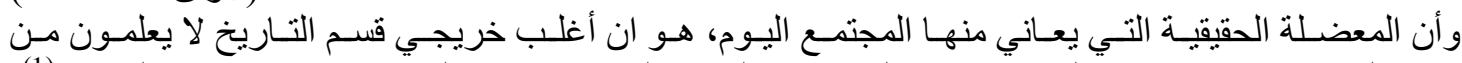

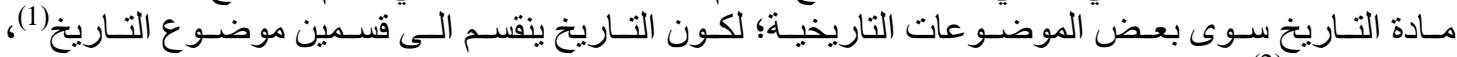

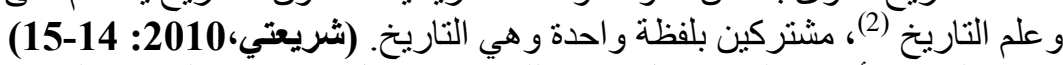

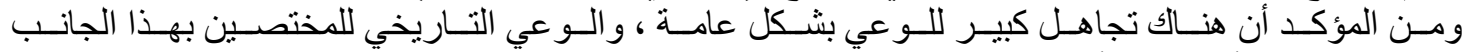

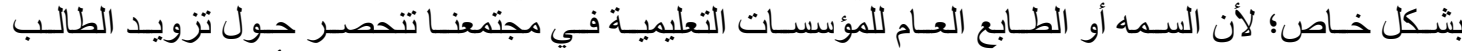

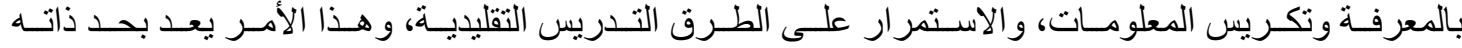

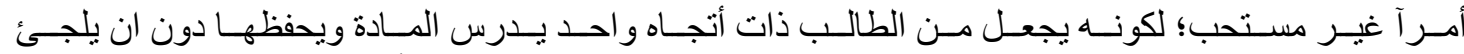

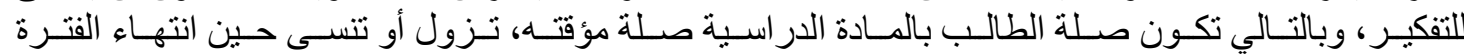

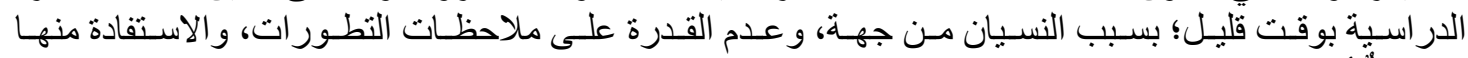

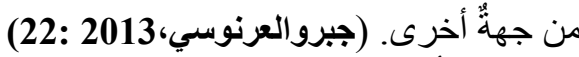

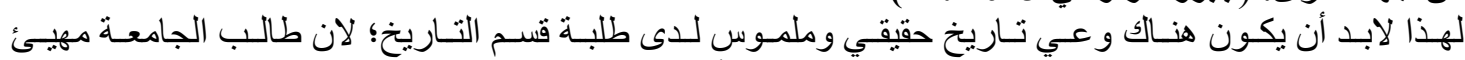

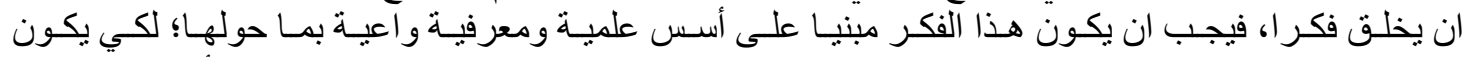

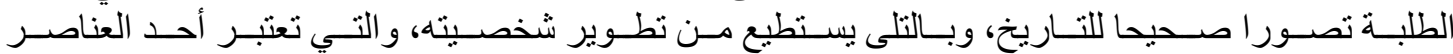

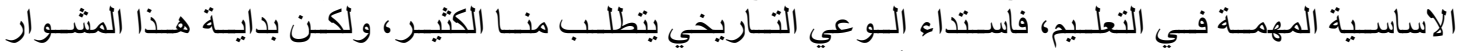

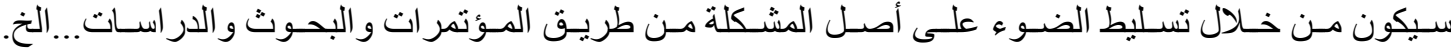

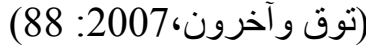

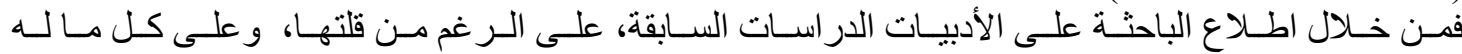

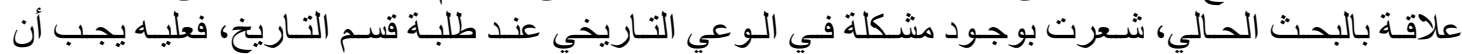

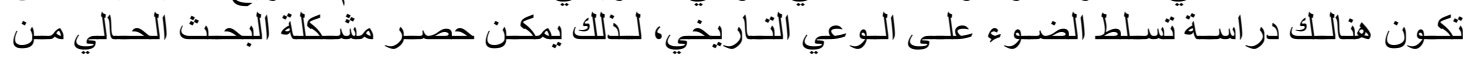

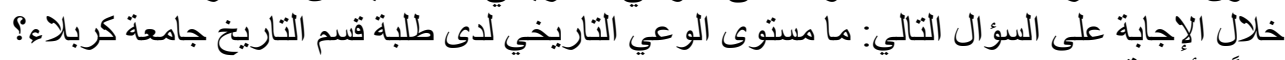

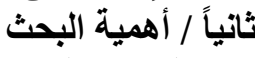

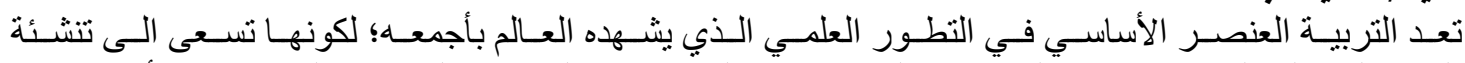

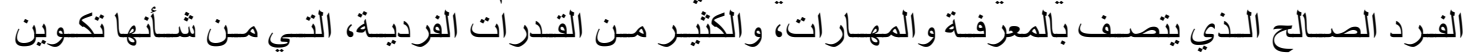

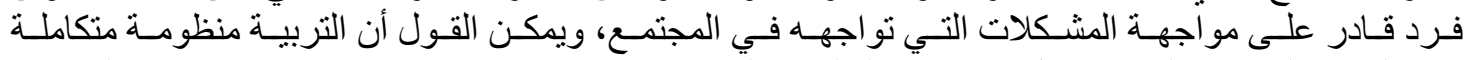

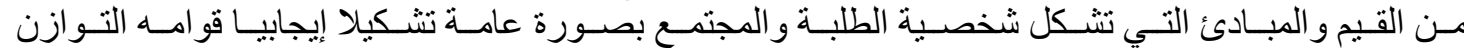

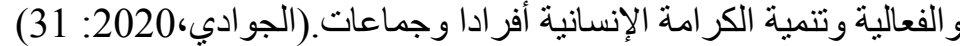

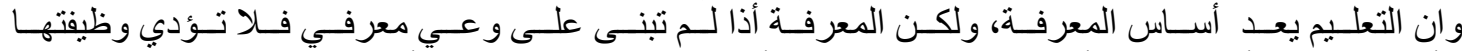

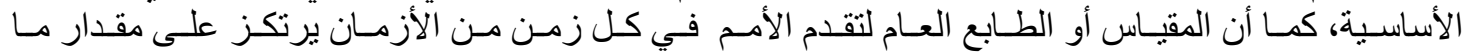

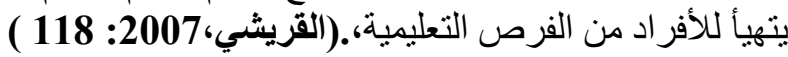

(1) يتعلق موضوع التاريخ بالظو اهر، و الحقائق، و العلاقات، و الو لادات، و الوفيات، و غير ها.

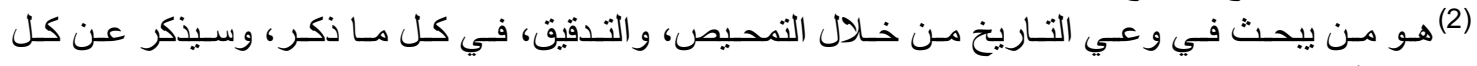
ظاهرة، أو حادثة تاريخية. 


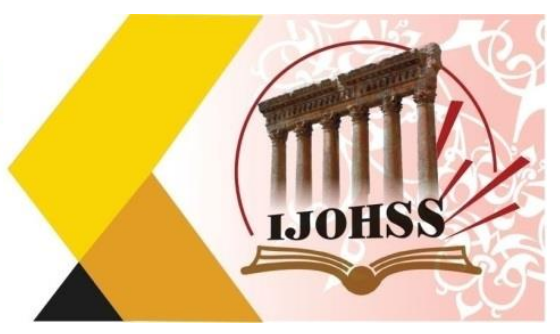

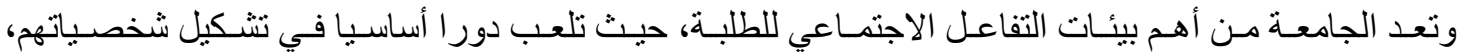

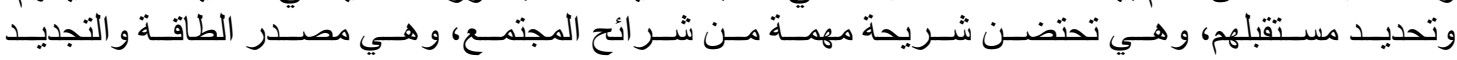

والانتاج (الجنابي، ونابن 2021: 144)

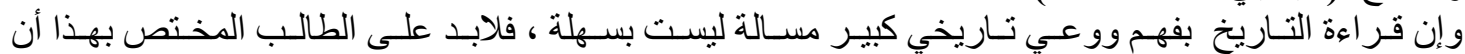

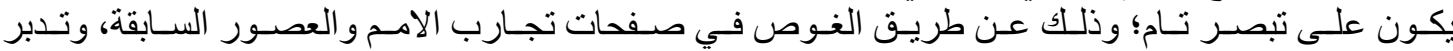

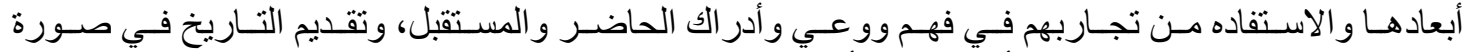

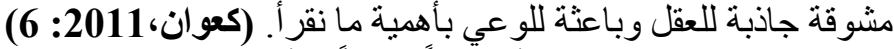

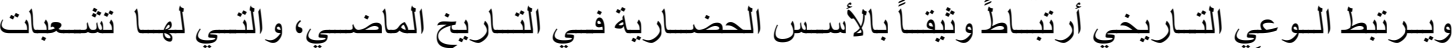

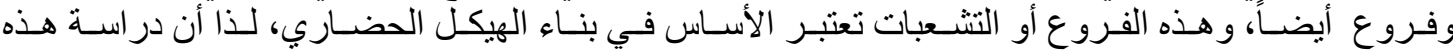

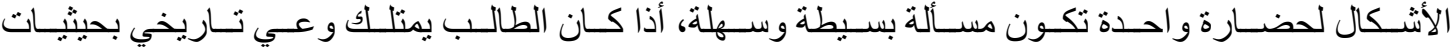

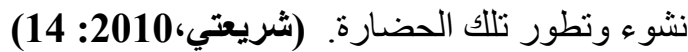

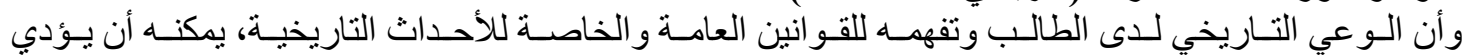

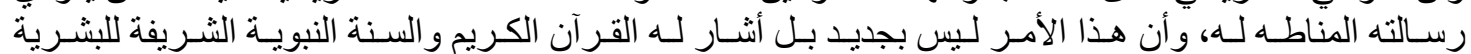

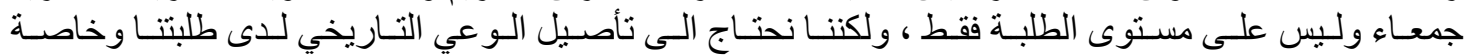

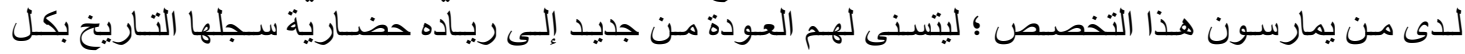

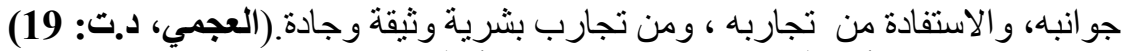

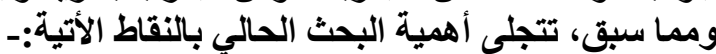

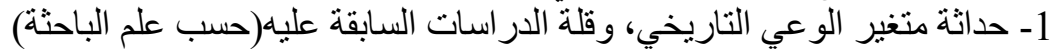

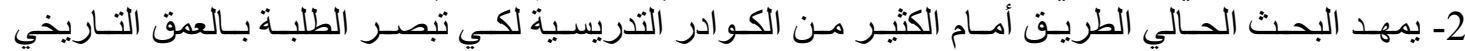
وليس القر اءة السطحية للتاريخ.

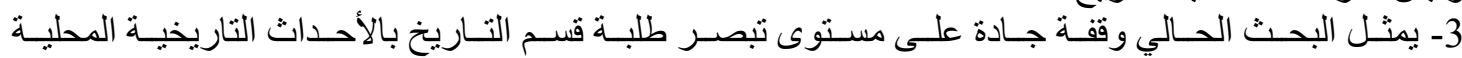
و الإقليمية و العالمية.

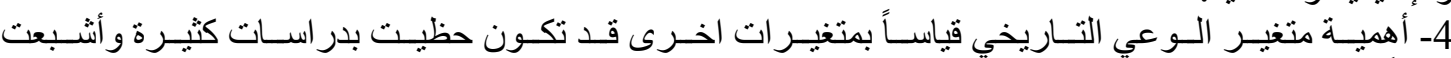
علمياً. ثالثاًاًأ هداف البحث

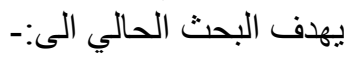

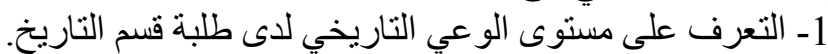

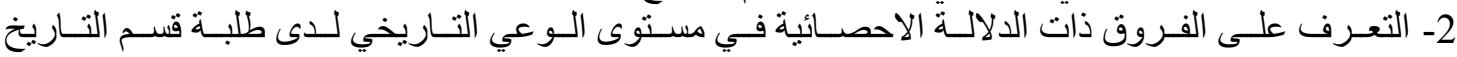
تبعا لمتغيري الجنس (ذكور ،اناث) و المرحلة (اولى، ثانية ، ثالثة ، رابعة).

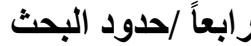
بتحدد البحث الحالي بالحدود الأتية:

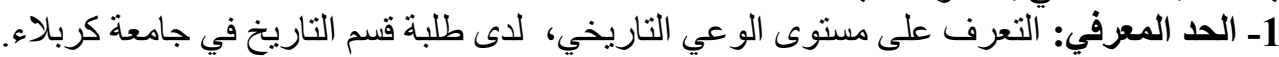

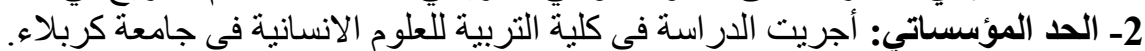

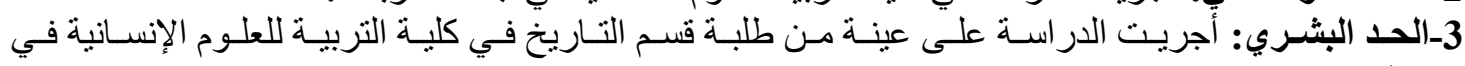

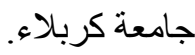
4-العد الزماني: أجريت الدراسة خلال العام الدراسي(2020-2021).

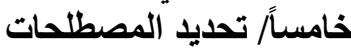
ستقوم الباحثة بتعريف المصطئ المصلحات الو اردة في عنوان البحث وكالأتي:

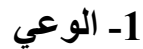

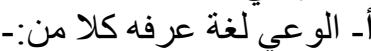

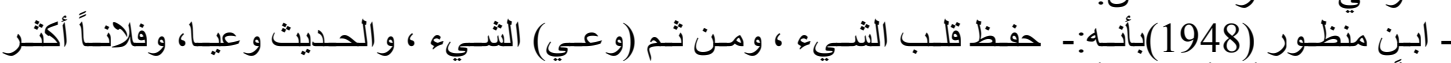

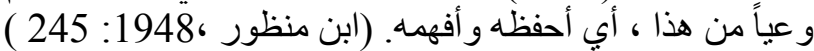

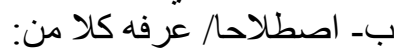




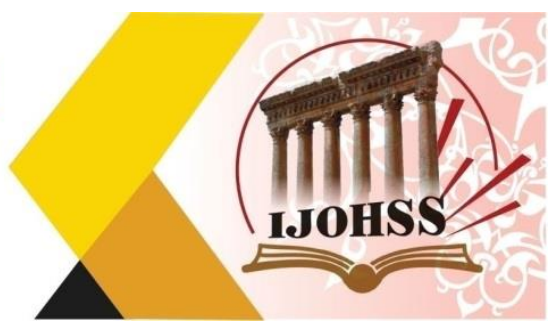

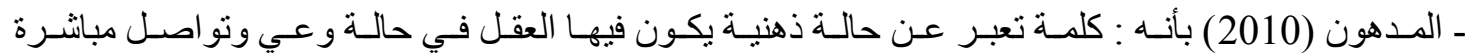

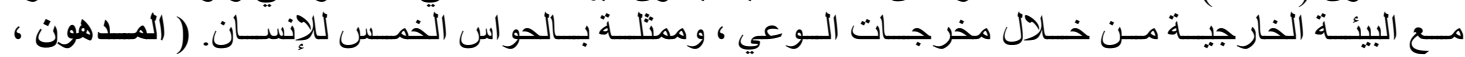

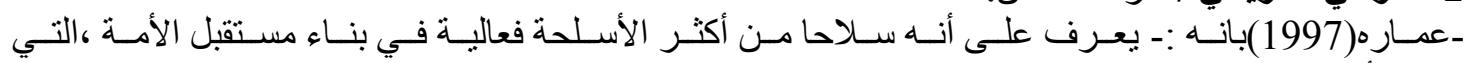

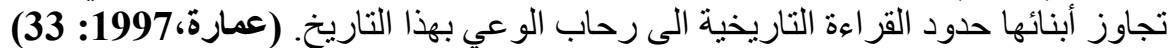

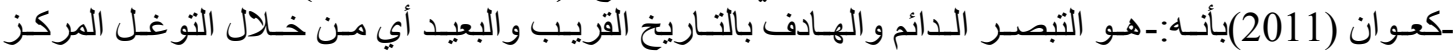

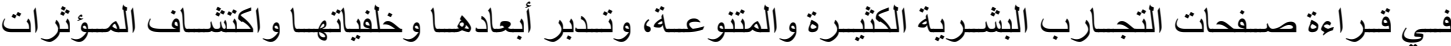

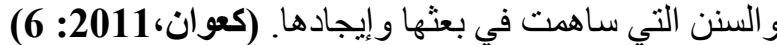

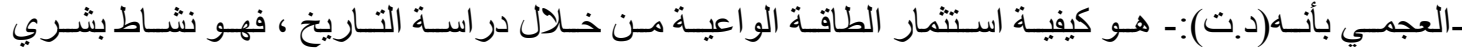

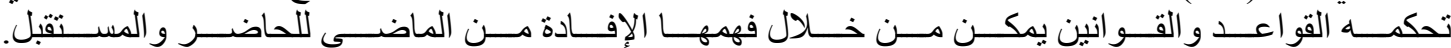

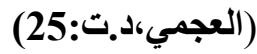

\section{الفصل الثاني/ دراسات سابقة}

\section{دراسات عربية

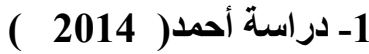

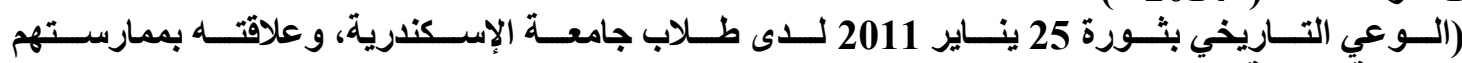

المواطنة النشطة).

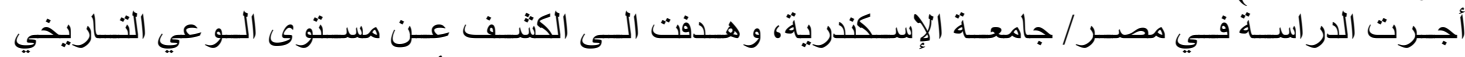

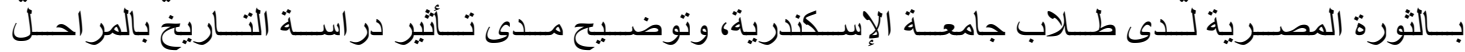

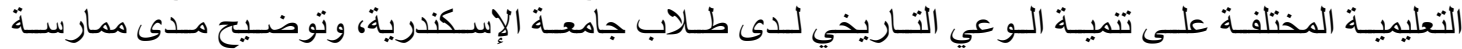

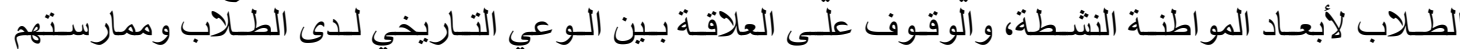

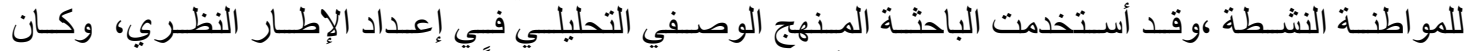

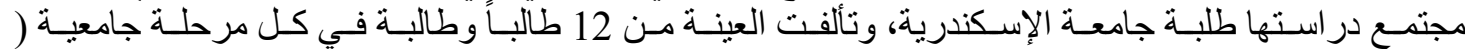

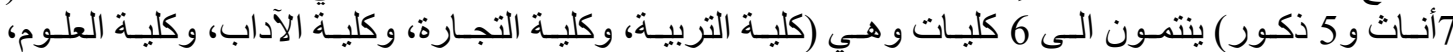

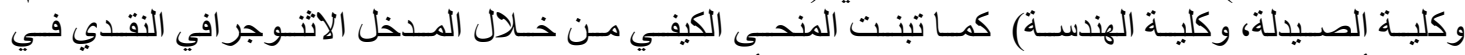

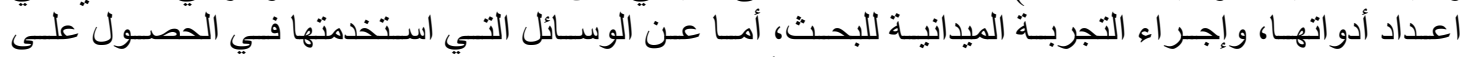

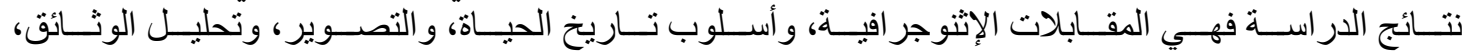
وتوصلت الدر اسة إلى نتائج كان منها:-

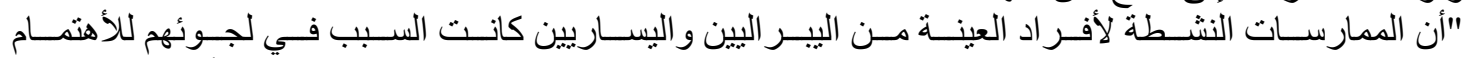

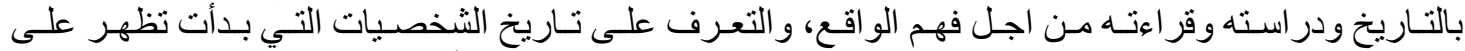

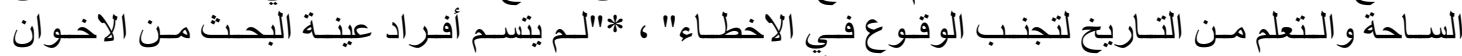

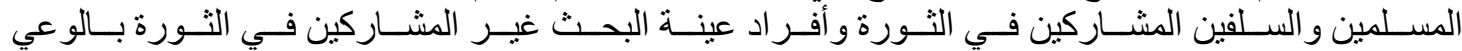

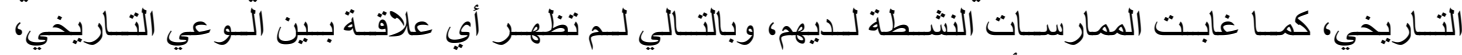

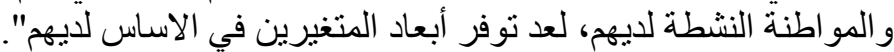

2- دراسة الشعراوي وآخرون (2019)

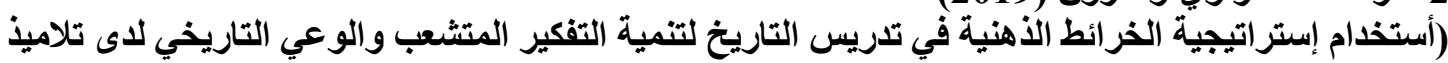
الصف الثاني الإعدادي)

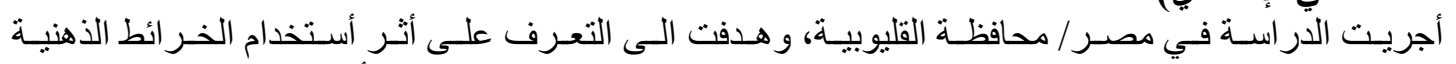

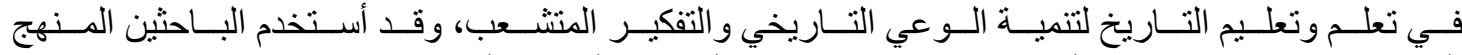

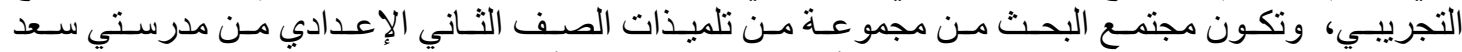

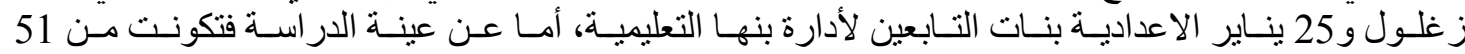




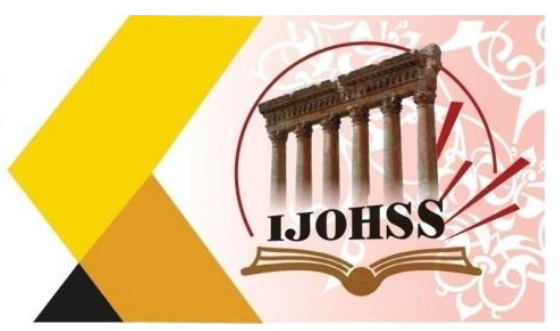

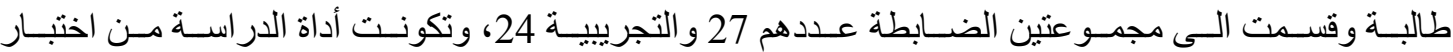

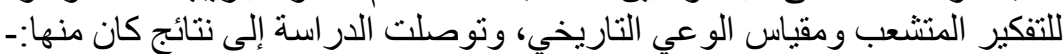

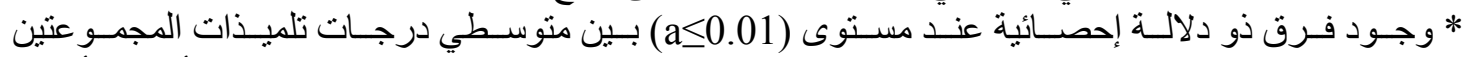

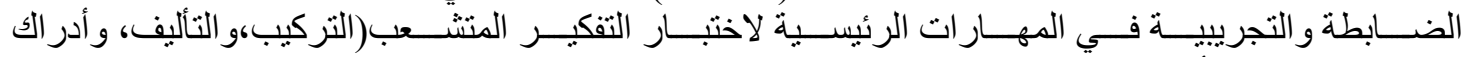

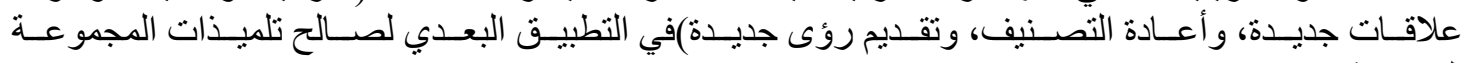
التجريبية. ـ - دراسة أجنبية 1- 1 فضلى وآخرون (2021) (تأثير طريقة سوروجان فرون في تعلم التاريخ لزيادة الفهم التاريخي والوعي التاريخي)

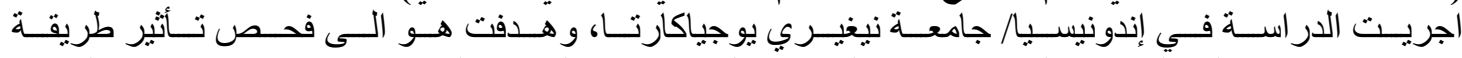

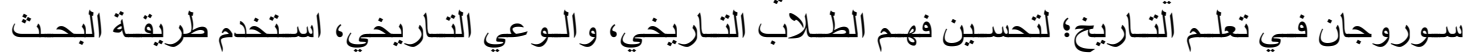

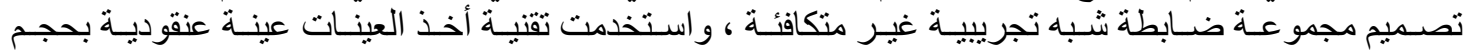

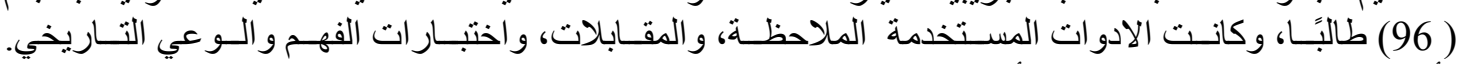

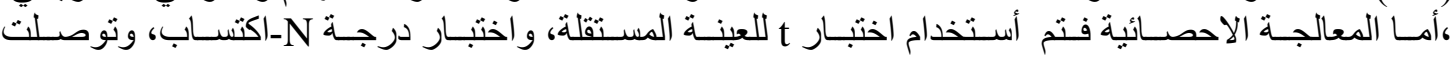

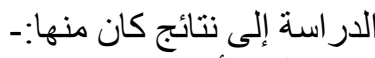

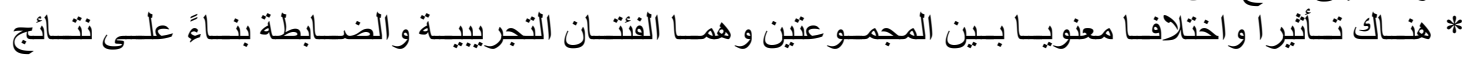

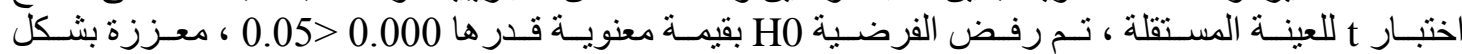

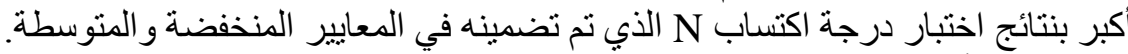

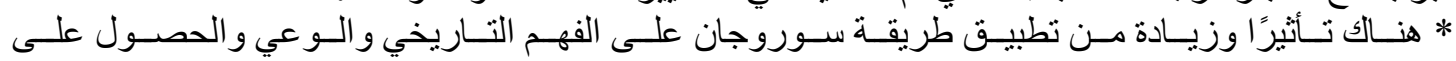

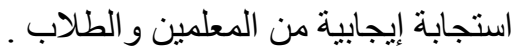

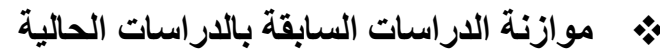

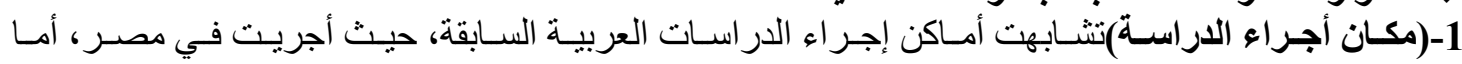

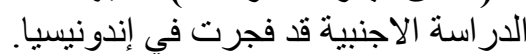

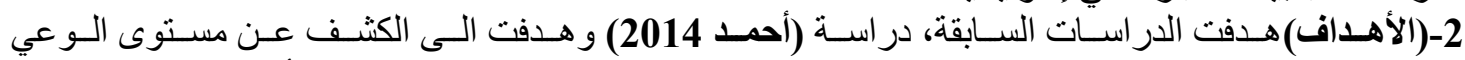

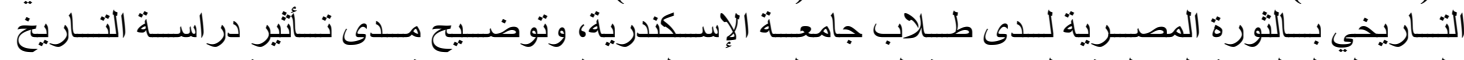

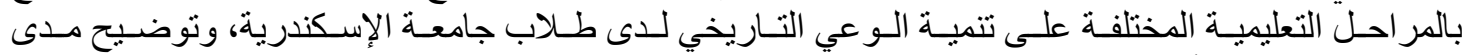

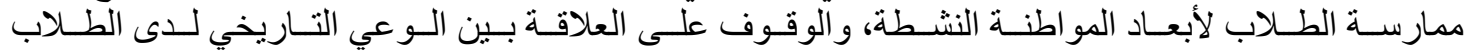

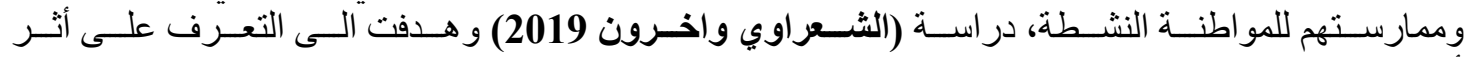

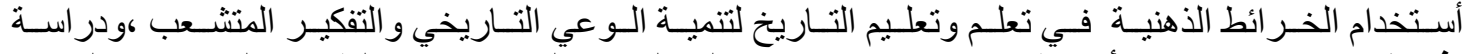

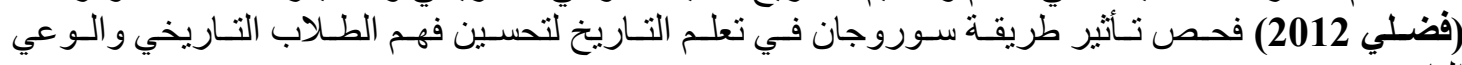

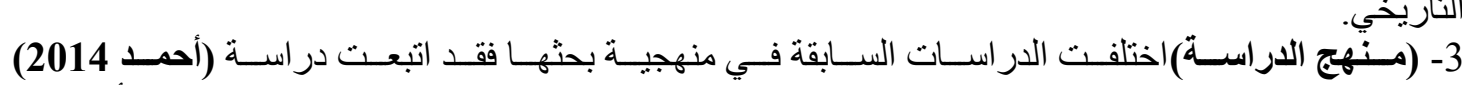

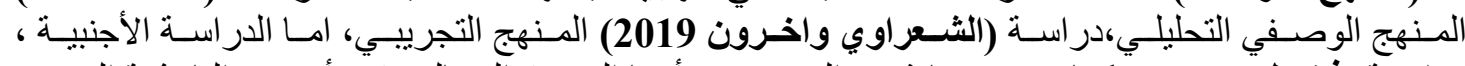

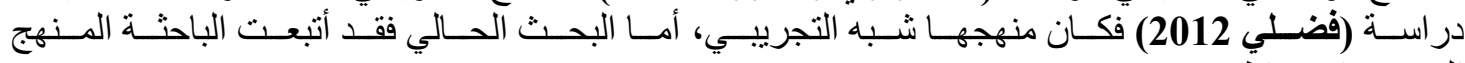
الوصفي الارنباطي.

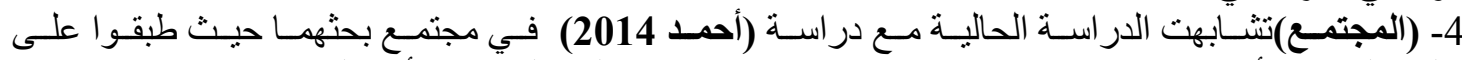

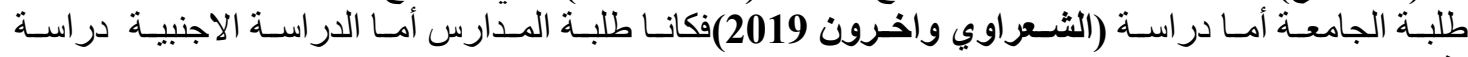
(فضلي 2012) فجمعت الطلبة والمعلمين. 5- (العينة)تباينت الدر اسات السابق في حجمة العينة التي اعتمدت، كلا حسب در استه.

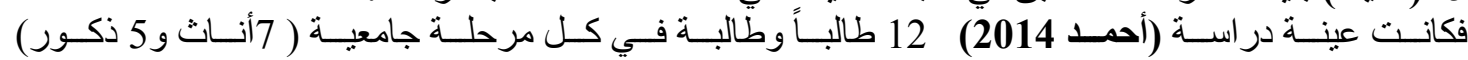

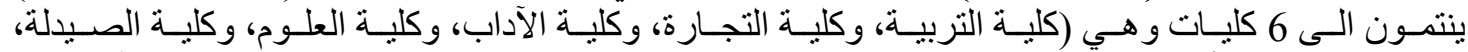

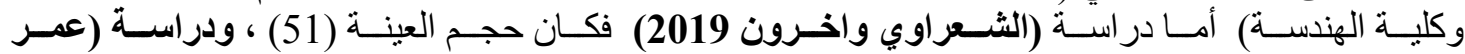




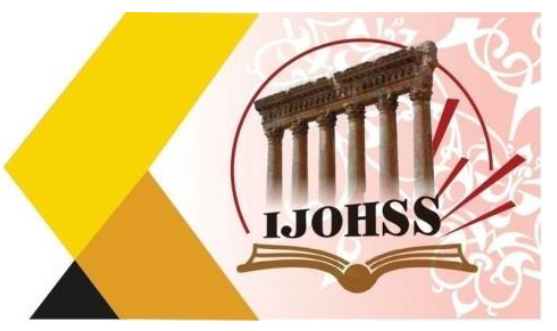

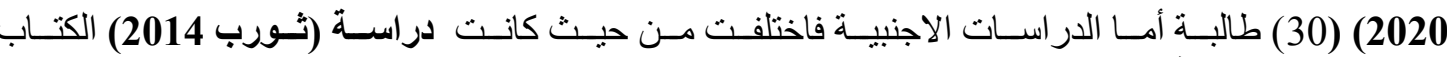

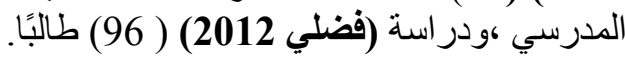

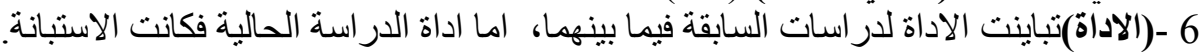

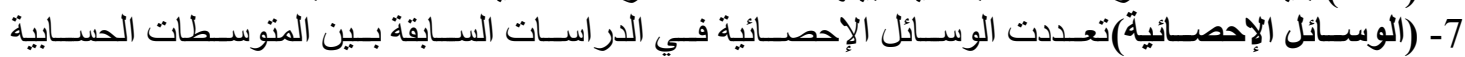

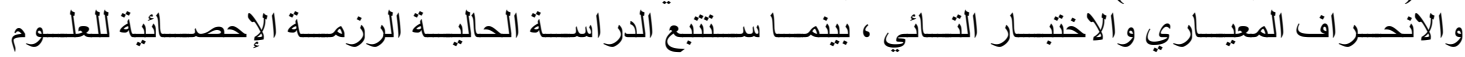

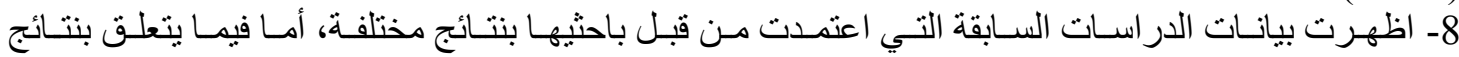

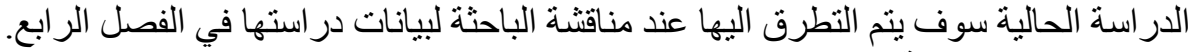

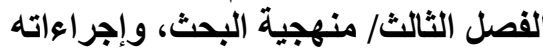
أولآ/منهجية البحث (Method Of The Research)

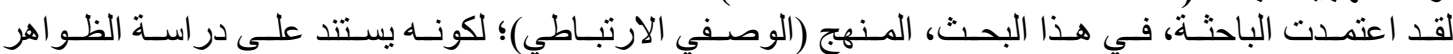

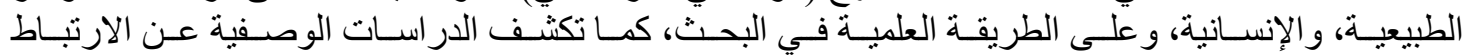

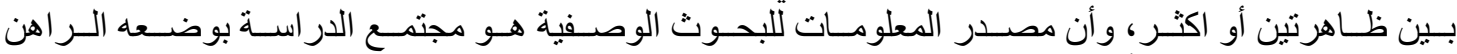

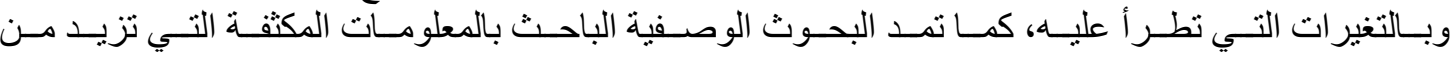

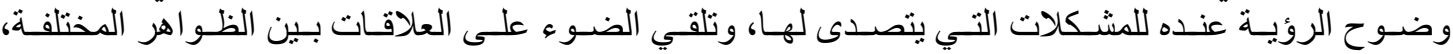

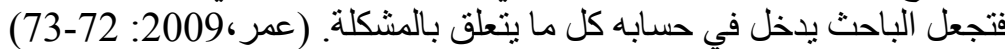
أ-مجتمع البحث.(Population Of The Research)

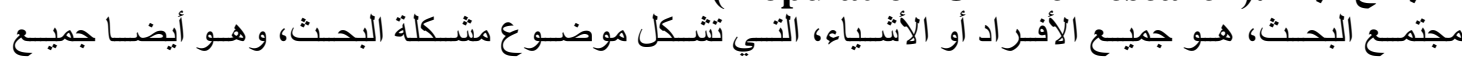

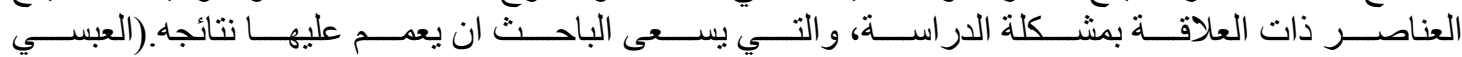

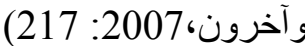

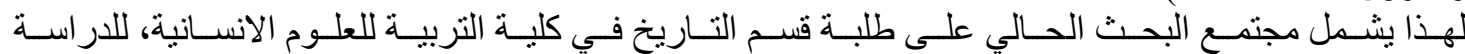

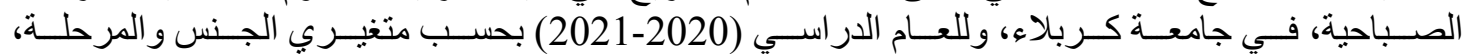
ويتألف مجنمع البحث من (507) طالبا وطالبة.

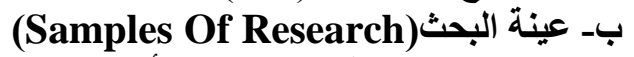

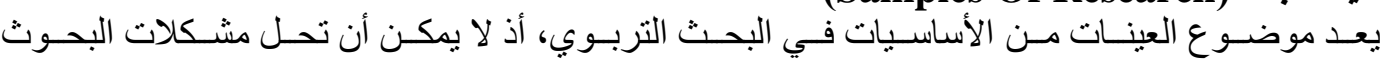

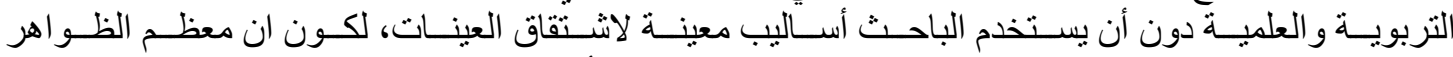

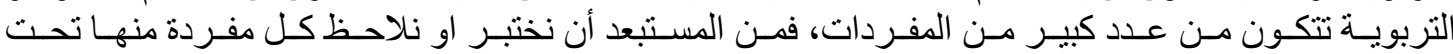

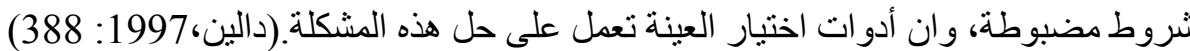

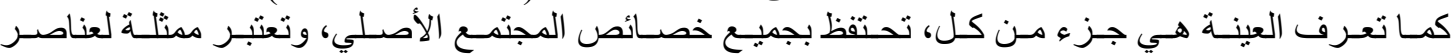
المجتمع أفضل تمثيل.(العبسي، 2007، 218، 218

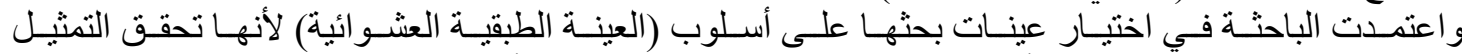

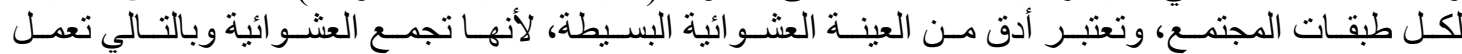

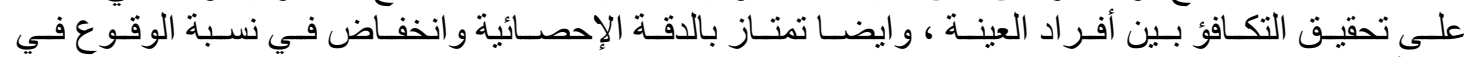

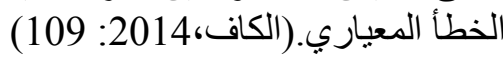

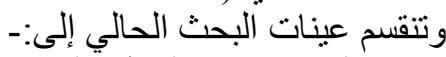

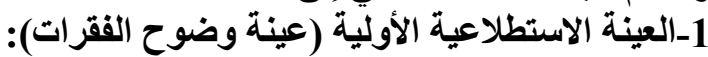

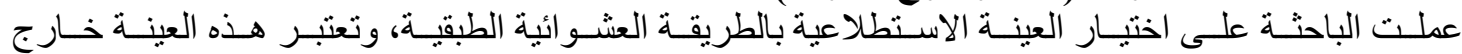

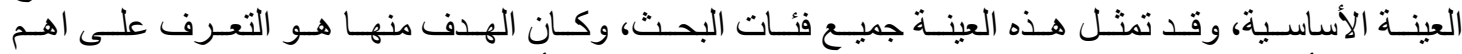

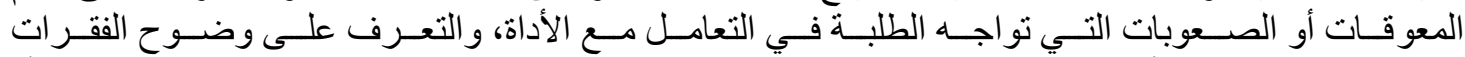

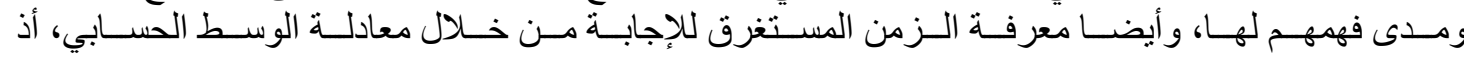

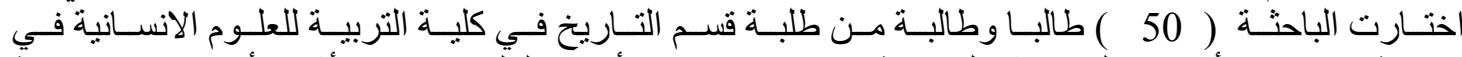

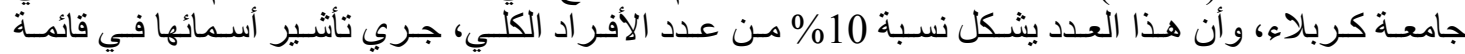




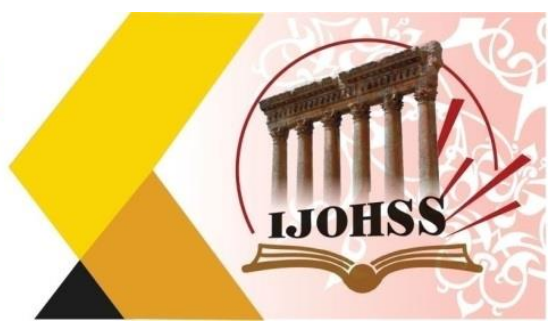

ـ العينة الاستطلاعية الثانية (عينة التحليل الإحصائي) :

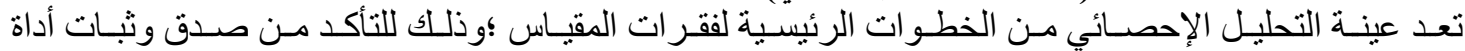

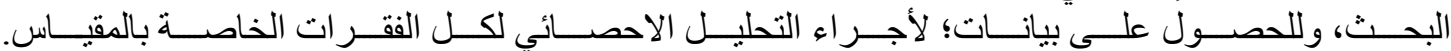

(Anastasi,1976:192)

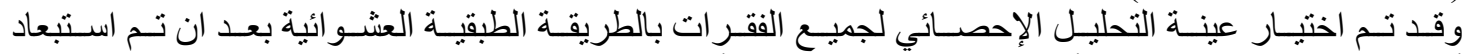

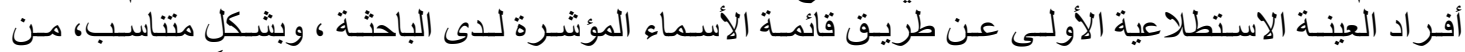

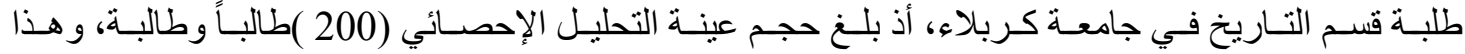
العدد يشكل نسبة(39\%) من المجموع الكارية الكلي للطلبة

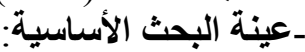

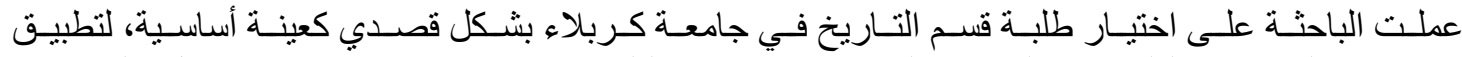

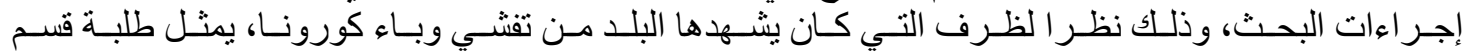

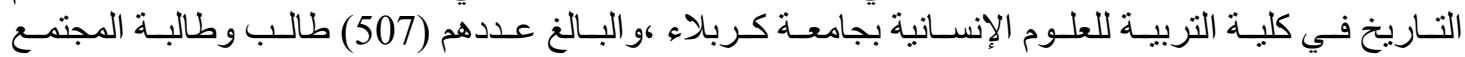

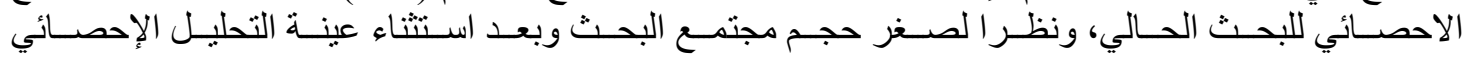

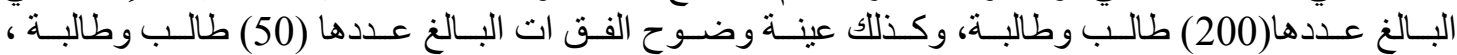

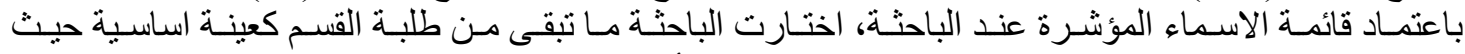

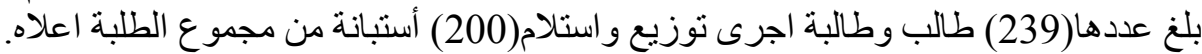

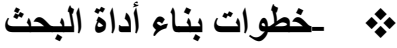

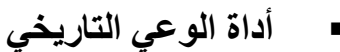
أتبعت الباحثة في بناء أداة متغير الوعي الوعي التاريخي الخطو ات الأتية:-

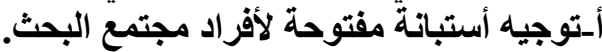

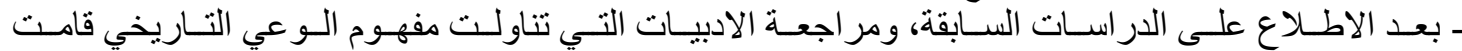

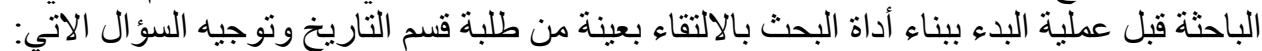

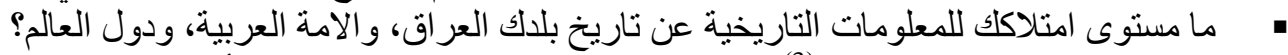

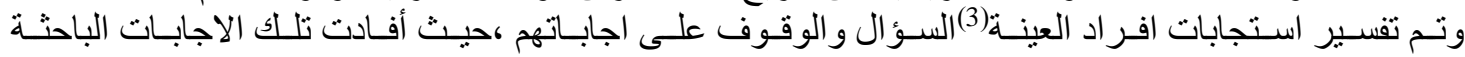
كثير ا في بناء اداة البحث الحابت الني.

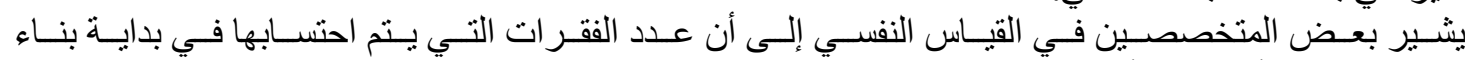

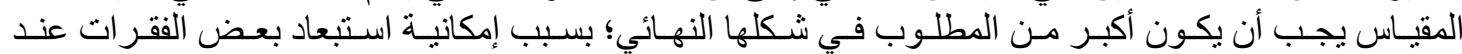

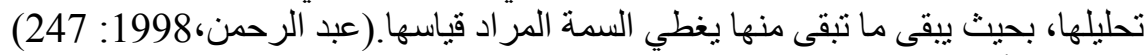
ب-وصف أداة الوعي التاريخي:

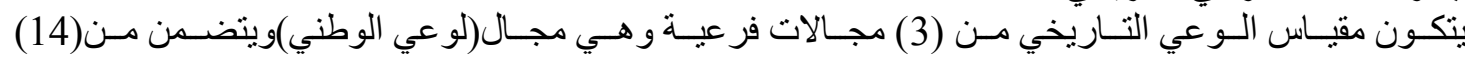

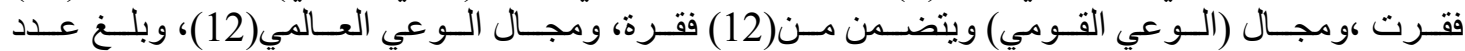

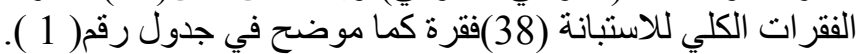
جدول (1) يبين مجالات أداة الوعي التاريخي

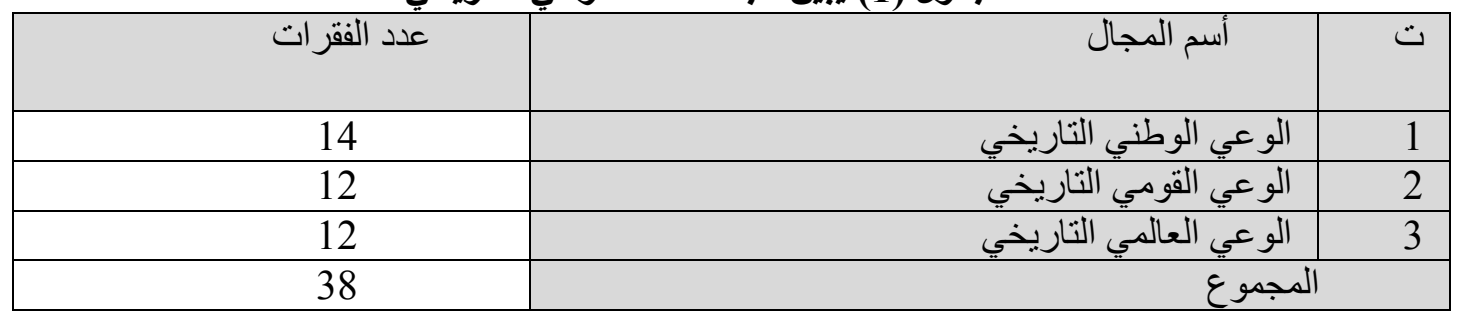




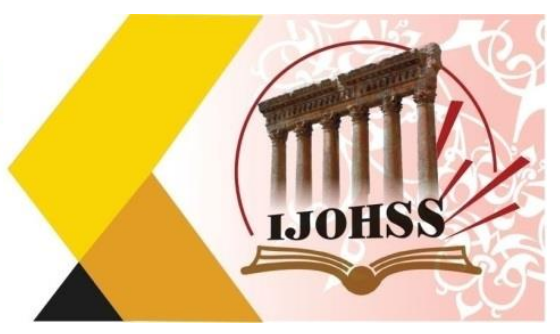

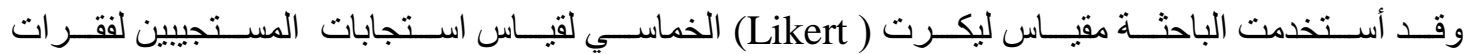

الاستبيان. وحسب ما موضح في الجدول(2) البرة جدول (2) يوضح درجات مقياس ليكرت لبدائل أستبانة الوعي التاريخ

\begin{tabular}{|c|c|c|c|c|c|}
\hline لا تتطبق & تتطبق & تنطبق عليّ أحياناً & تنطبق عليّ غالباً & كثنبراً & البدائل \\
\hline 1 & 2 & 3 & 4 & 5 & الارجة \\
\hline
\end{tabular}

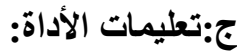

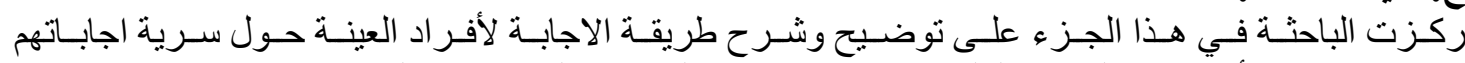

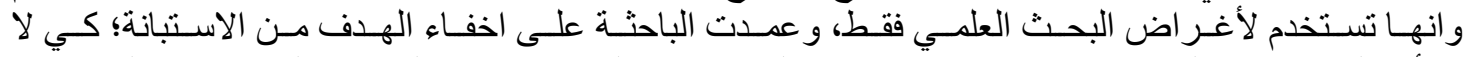

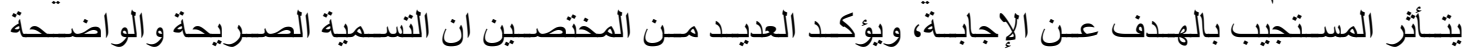

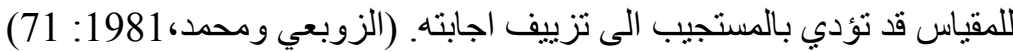

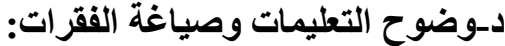

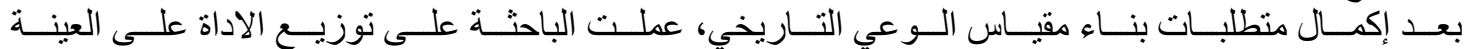

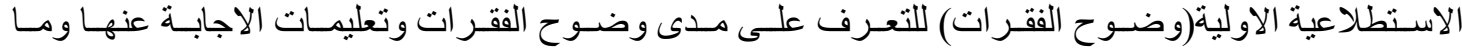

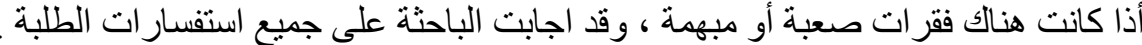

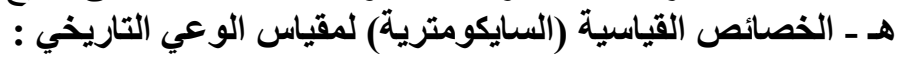

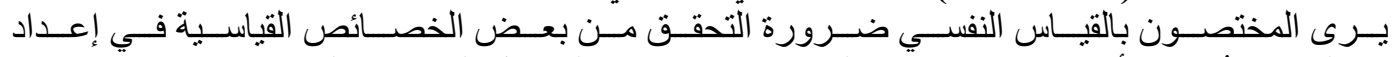

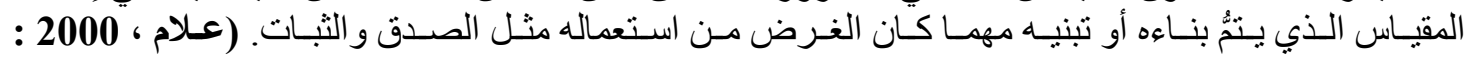
فقد تحققت الباحثة من الخصائص السايكومترية لمقياس الوعي التاريخي على النحو الآتي:

أولاً : صدق المقياس Scale Validity

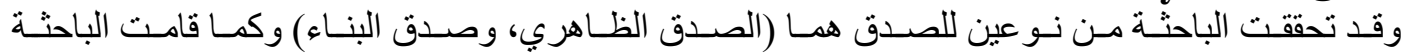

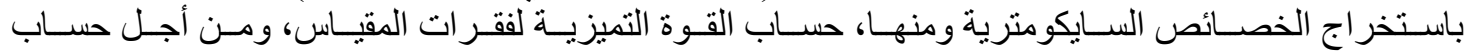

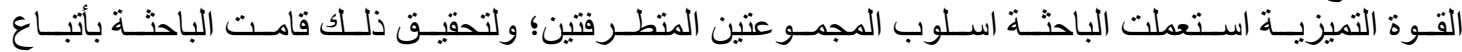

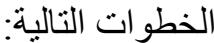

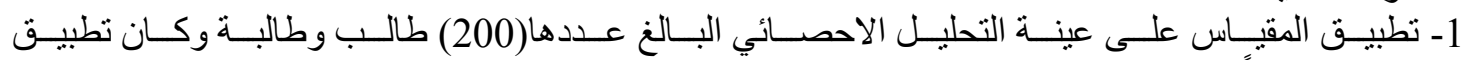
المقياس الكترونياً.

2- تصحيح استمار ات المقياس وحساب الدرجة الكلية الكية لكل استمارة بصورة الكترونية.

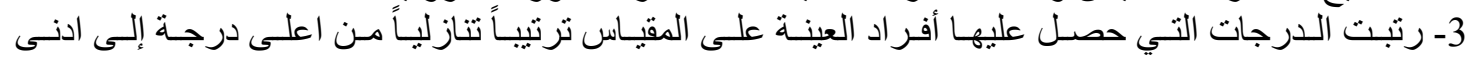
درجة.

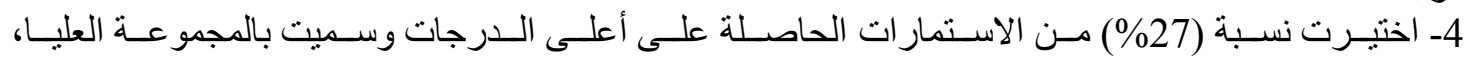

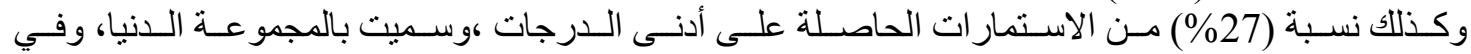

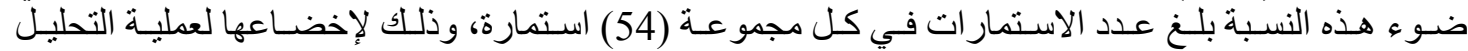

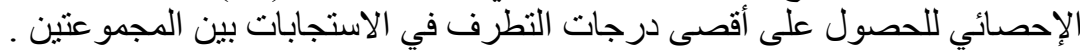

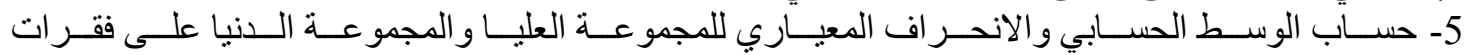

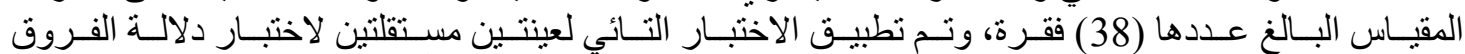

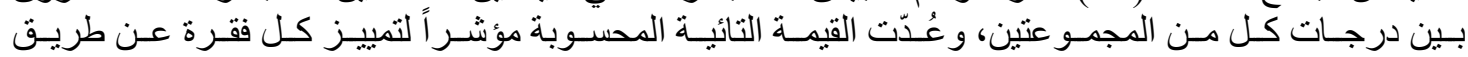

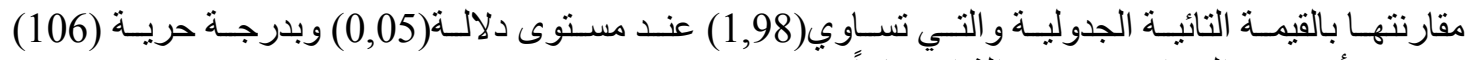
وقد تبين أن جميع الفقر ات مميزة ودالة الحئة إحصائياً. 
العداد(22) يوليو 2021

ISSN: $2415-\mathbf{4 8 2 2}$

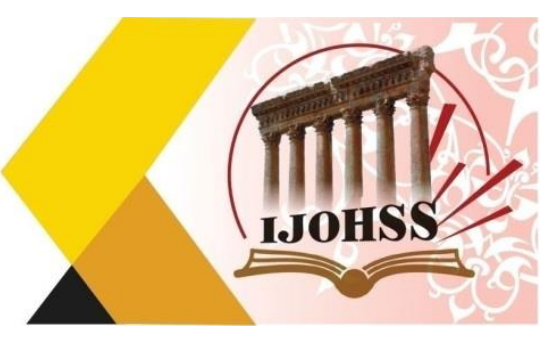

ثناتياً: ثبات المقياس Scale Reliability. ولغرض إيجاد ثبات مقياس الوعي التاريخي فقد اعتمدت الباحثة على طريقتين هما: أولاً : طريقة إعادة الاختبار. ثانياً : معادلة : ألفا كرونباخ للاتساق الداخلي.

\section{الفصل الرابع/ عرض النتائج وتفسيره}

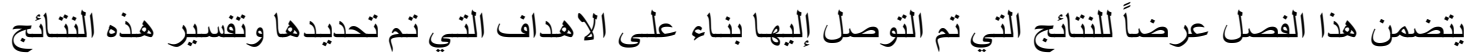

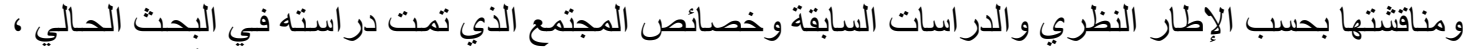

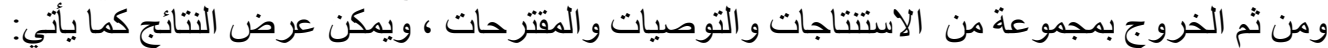

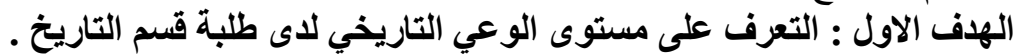

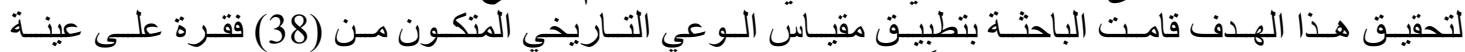

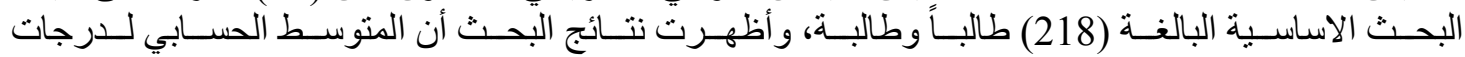

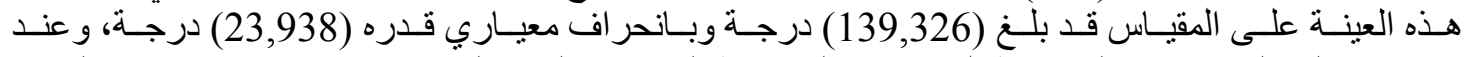

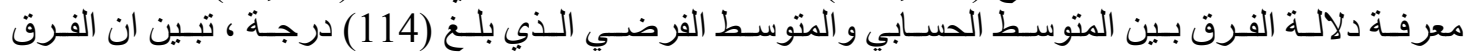

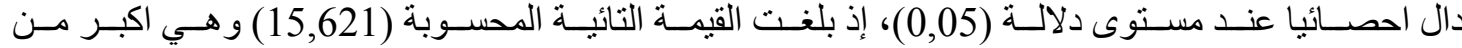

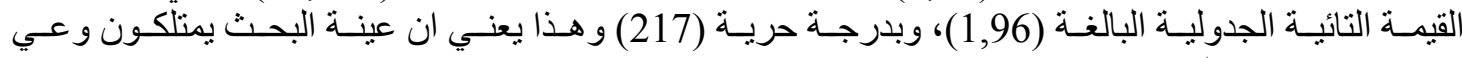
تاريخي بمستوى عالي.

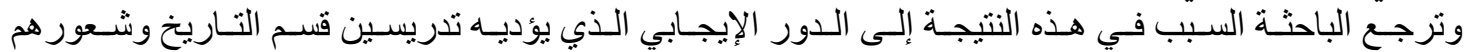

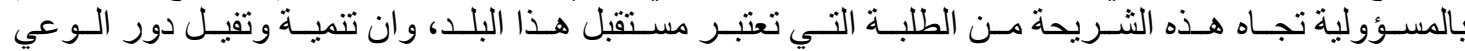

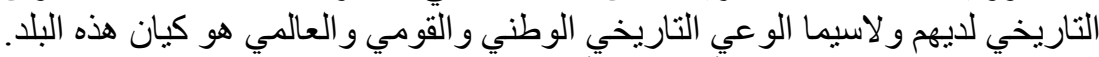

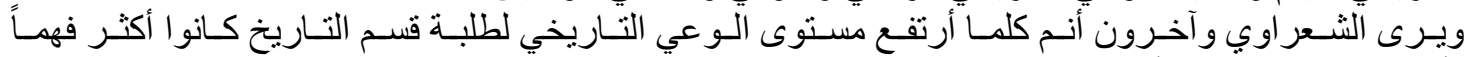

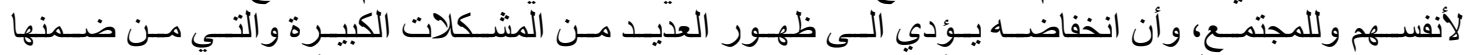

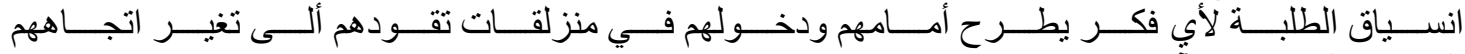

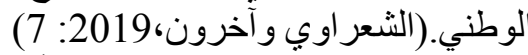

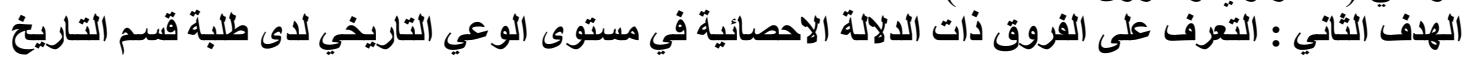

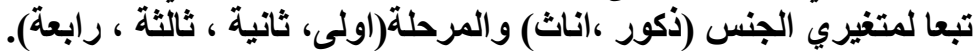

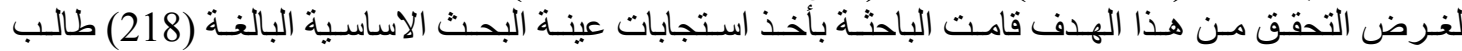

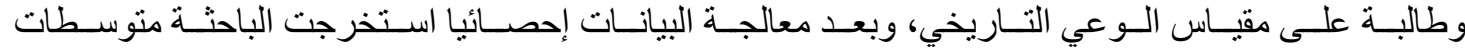

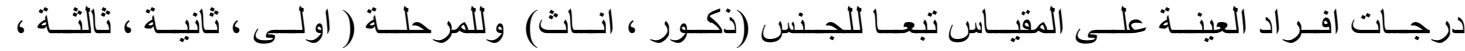

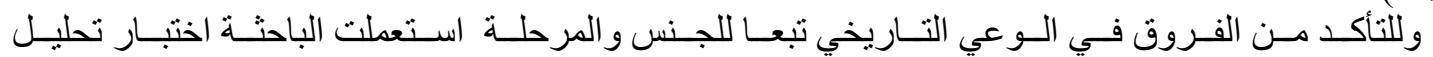

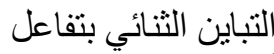

أظهرت نتائج تحليل التباين الثنائي المعطيات الآتية:

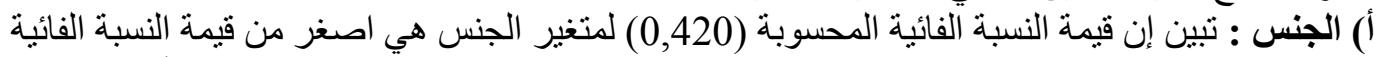

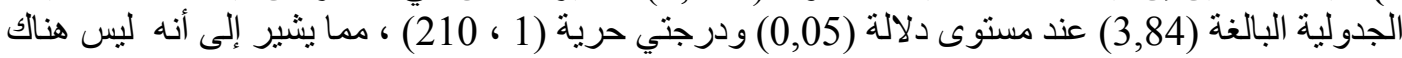

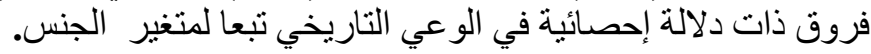

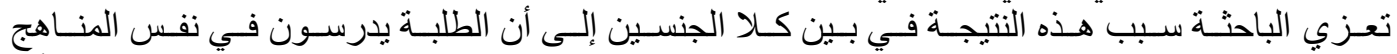

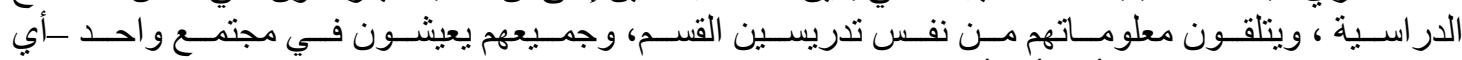
هو يتهم موحدة ،فكل ما ذكر أدى ألى أنه لا يوجد فرقوق ذات دلالة احصائية بين الذكور و الآناث. ب) متغير المرحلة

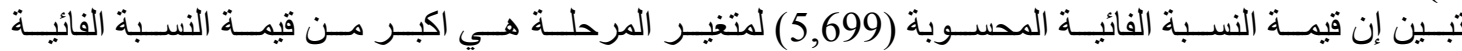

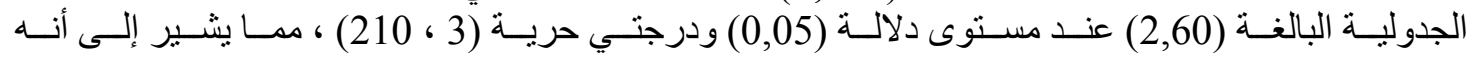




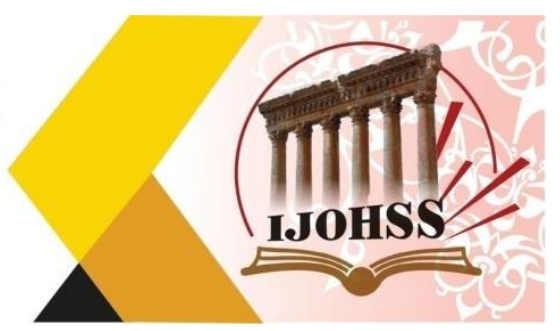

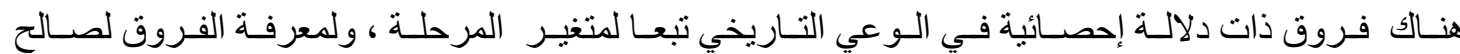
أي مرحلة استخدمت الباحثة اختبار شيفية للمقارنات البرات البعدية.

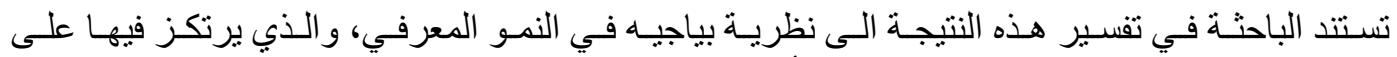

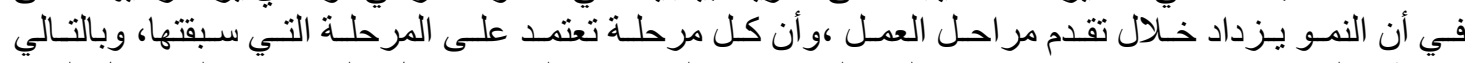

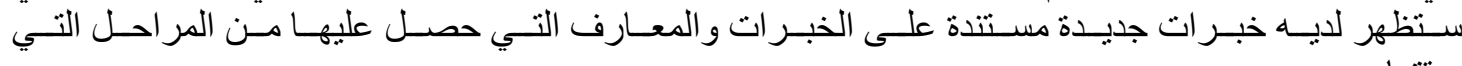
سبقتها.

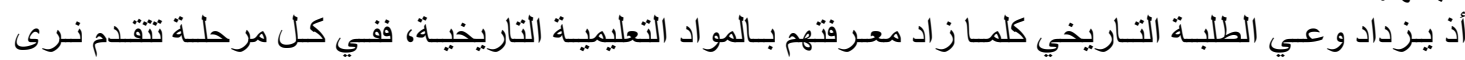

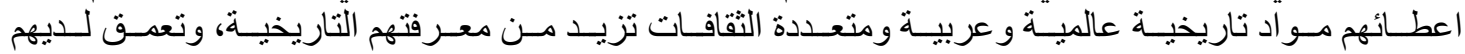

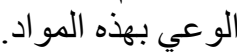
• الاستنتاجات والتوصيات والمقترحات • الاستنتاجات (Conclusion)

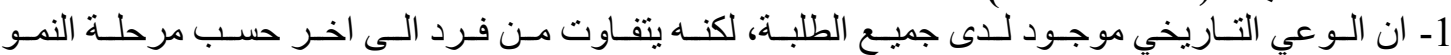

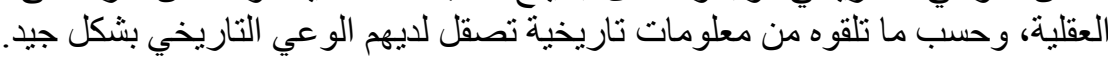

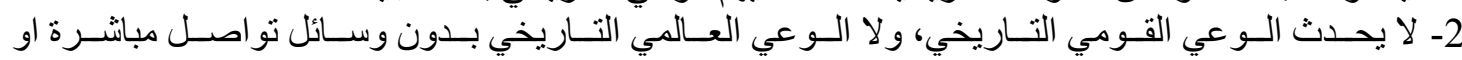

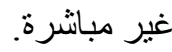
3- الوعي التاريخي الحقيقي هو حل لمشكلة الطائفية.

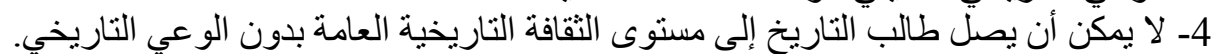

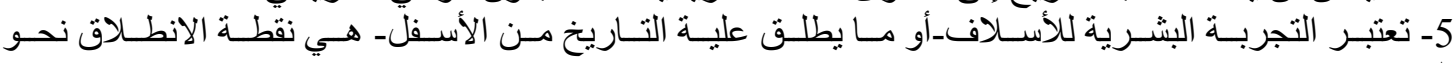

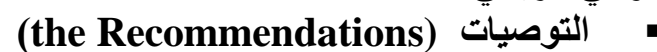

في ضور النتائج التي توصل اليها البحث ،أوصت الباحثة بعدد من التوصيات ومنها:

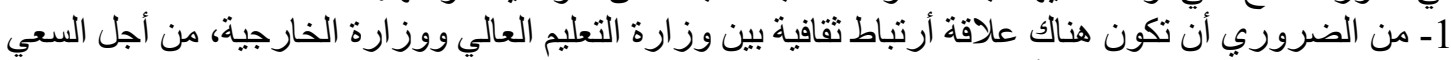

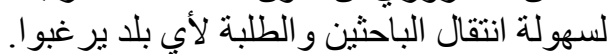

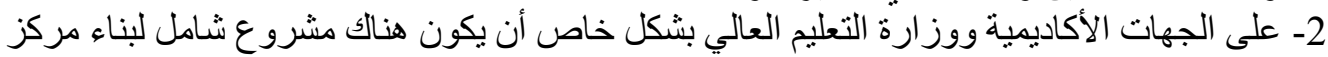

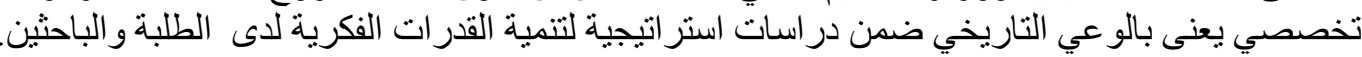

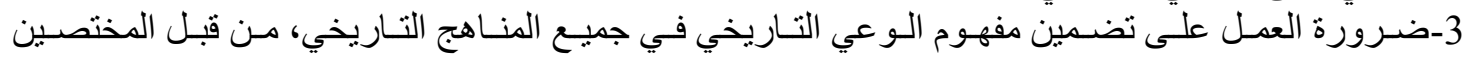
في تطوير المناهج ليتبصر الطلبة في معرفة ماهية هذا المفهوم وما يكمن في طياتها.

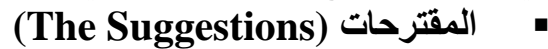

1- النظر بعناية من أصحاب الاختصاص في تفعيل وتحفيز الو عي التاريخي لدى الطلبة من خلال مشاركتهم

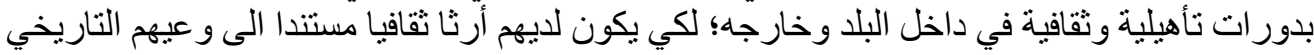

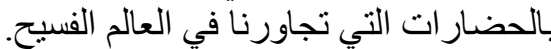

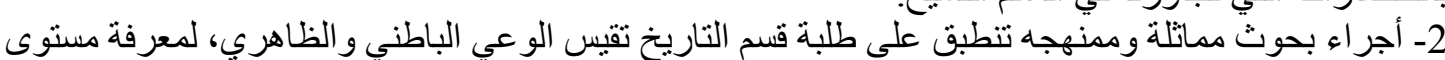

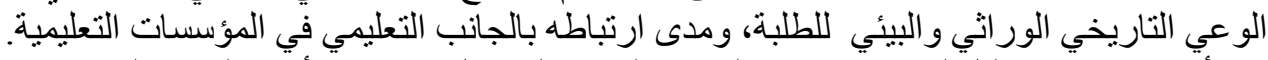

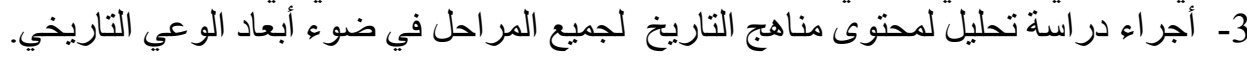

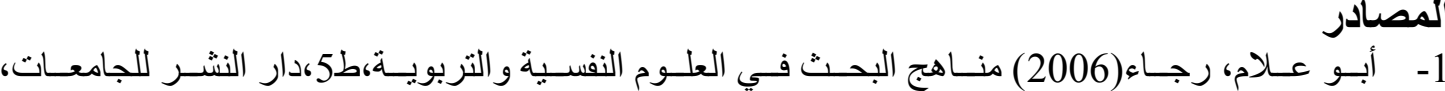

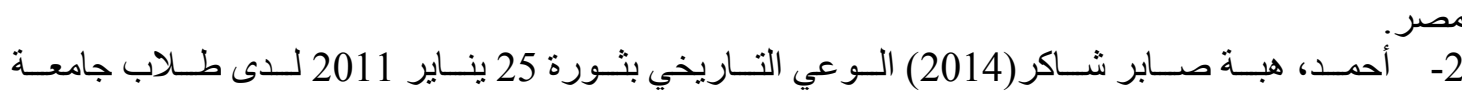

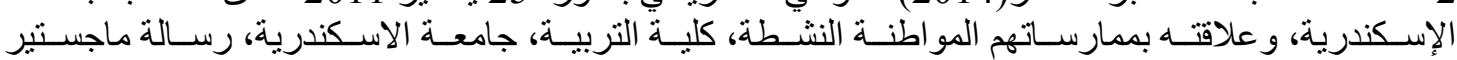

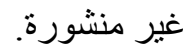

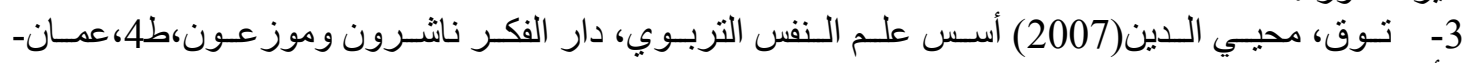

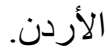




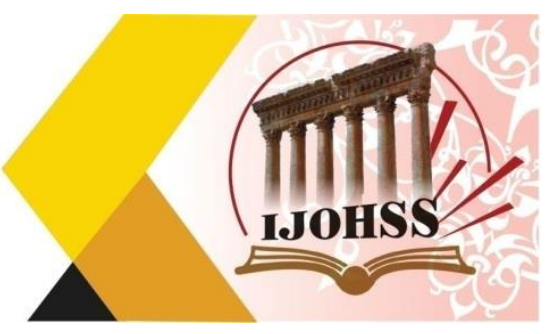

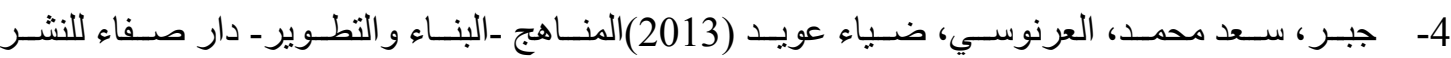

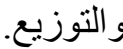

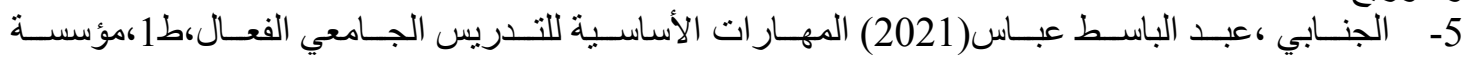

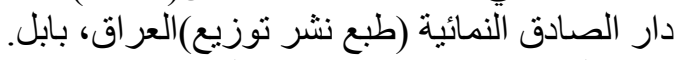

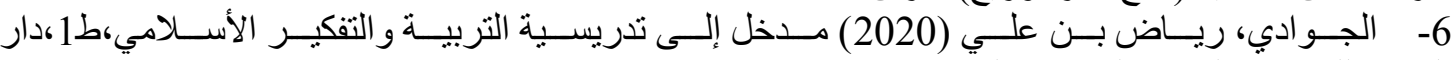
التجديد للطابعة و النشر و التنوزيع والترجمة.

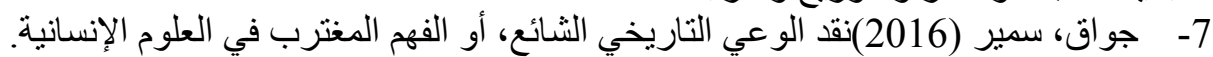

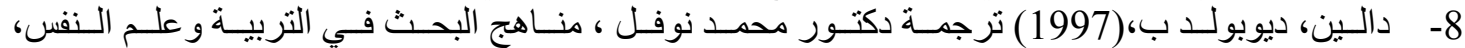
مكتبة الانجلو المصرية_القاهرة

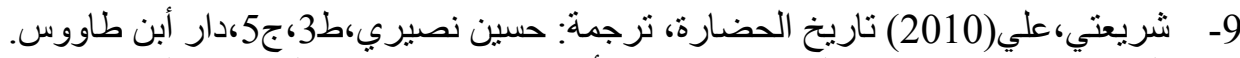

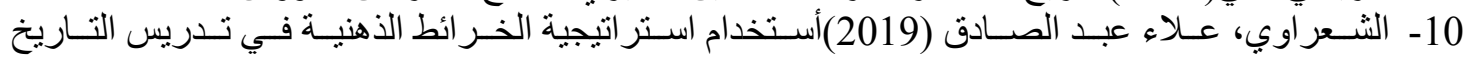

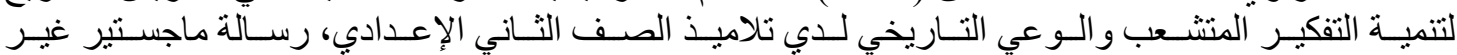

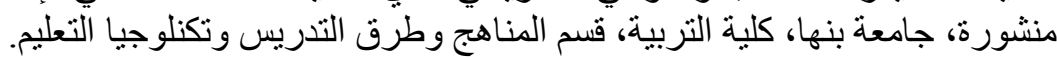

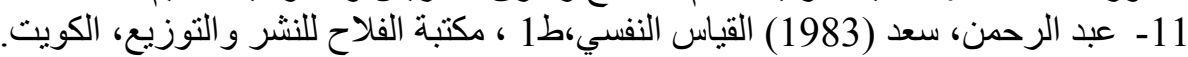

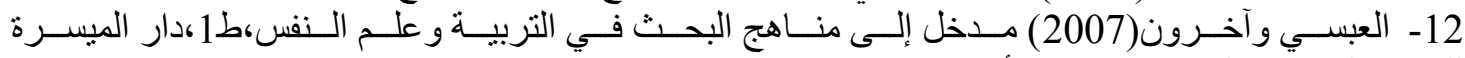
للنشر و التوزيع و الطباعة، عمان-الأردن.

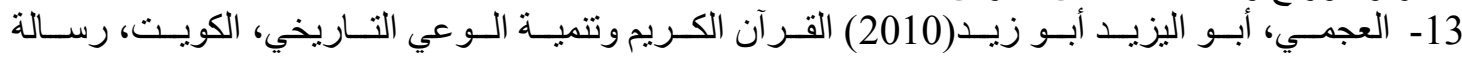

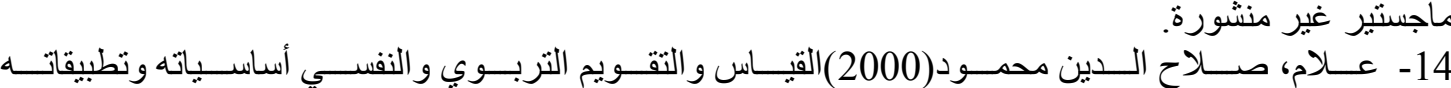
وتوجهاته المعاصرة ،ط1،دار الفكر العربي، القاهرة.

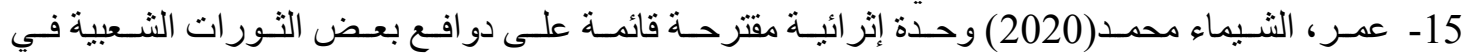

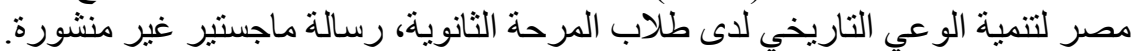

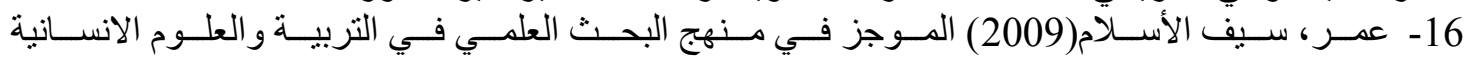

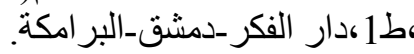

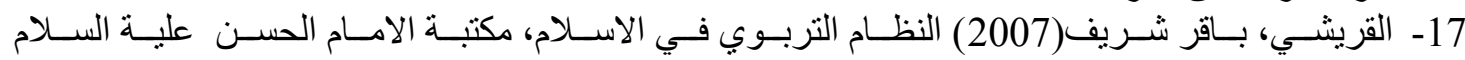

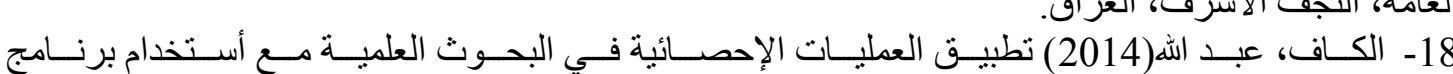

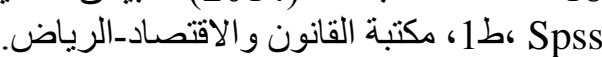

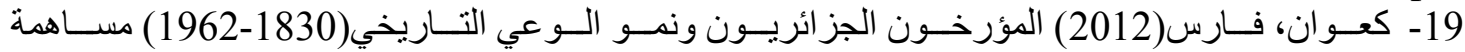

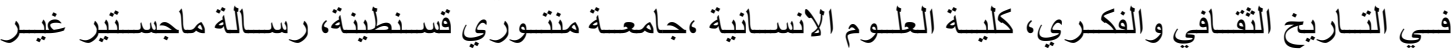
منشورة. 20- معجم علم النفس و التربية(1984) الهيئة العامة لنؤون المطابع الأميزية،ج1. 21-Fadli, Muhammad Rijal, et al. (2021) The effect of the Surugan method in learning history to increase historical understanding and historical awareness, International Journal of Evaluation and Research in Education (IJERE) Vol. .((10), I)ssue (10) 


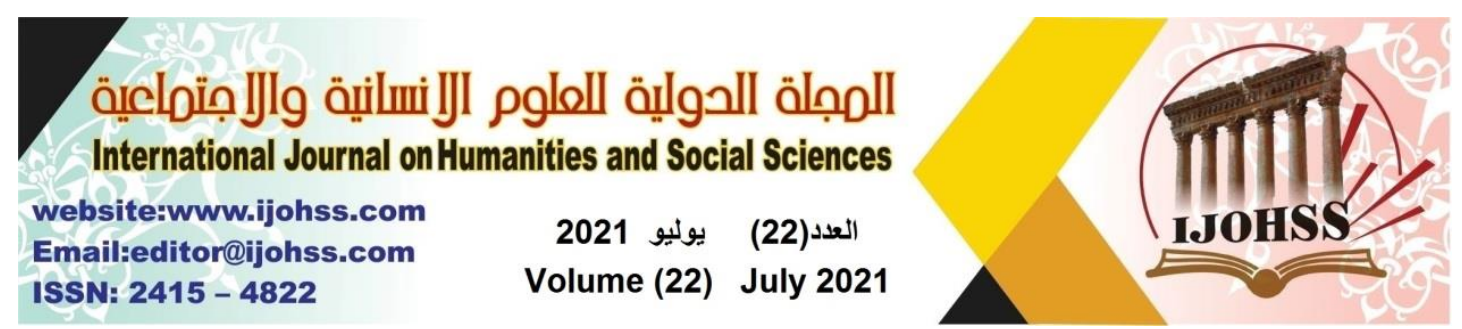

\section{References}

1-Abu Allam, Raja (2006) Research Methods in Psychological and Educational Sciences, 5th Edition, Universities Publishing House, Egypt.

2-Ahmad, Heba Saber Shaker (2014) Historical awareness of the January 25, 2011 revolution among Alexandria University students, and its relationship to their active citizenship practices, Faculty of Education, University of Alexandria, an unpublished master's thesis.

3-Touq, Mohieldin (2007) Foundations of Educational Psychology, Dar Al-Fikr Publishers and Distributors, 4th Edition, Amman - Jordan.

4-Jabr, Saad Muhammad, Al-Arnosi, Diaa Owaid (2013) Curricula - Construction and Development - Safaa Publishing and Distribution House.

5-Al-Janabi, Abdul Basit Abbas (2021) Basic Skills for Effective University Teaching, 1st Edition, Dar Al-Sadiq Developmental Foundation (printed, published, distributed), Iraq, Babylon.

6-Al-Jawadi, Riyad bin Ali (2020) Introduction to Teaching Education and Islamic Thinking, 1st Edition, Dar Al-Tajdeed for printing, publishing, distribution and translation.

7-Jawaq, Samir (2016) A critique of common historical awareness, or alienated understanding in the humanities.

8-Dallin, Diopold B. (1997), translated by Dr. Mohamed Nofal, Research Methods in Education and Psychology, Anglo-Egyptian Library - Cairo.

9-Shariati, Ali (2010) The History of Civilization, translated by: Hussein Nasiri, 3rd edition, 5th edition, Dar Ibn Tawoos.

10-Al-Shaarawy, Alaa Abdel-Sadiq (2019) Using the strategy of mind maps in teaching history to develop divergent thinking and historical awareness among secondgrade students, unpublished master's thesis, Benha University, Faculty of Education, Department of Curriculum, Teaching Methods and Educational Technology.

11-Abdul Rahman, Saad (1983) Psychometrics, 1st Edition, Al Falah Library for Publishing and Distribution, Kuwait.

12-Al-Absi and others (2007) Introduction to Research Methods in Education and Psychology, 1st Edition, Dar Al-Maysara for Publishing, Distribution and Printing, Amman - Jordan.

13-Al-Ajmi, Abu Al-Yazid Abu Zaid (2010) The Holy Qur'an and the Development of Historical Awareness, Kuwait, unpublished MA thesis.

14-allam, Salah Al-Din Mahmoud (2000) Educational and psychological measurement and evaluation: its basics, applications and contemporary trends, 1st Edition, Dar Al-Fikr Al-Arabi, Cairo.

15-Omar, Shaima Muhammad (2020) A proposed enrichment unit based on the motives of some popular revolutions in Egypt to develop historical awareness among high school students, unpublished master's thesis.

16-Omar, Seif Al-Islam (2009) Summary in the Scientific Research Methodology in Education and Human Sciences, 1st Edition, Dar Al-Fikr - Damascus - Al-Baramkeh. 


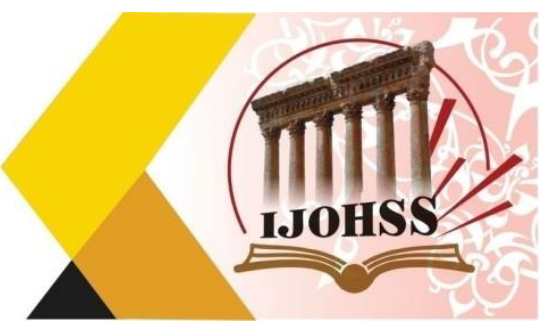

17-Al-Quraishi, Baqer Sharif (2007) The educational system in Islam, Imam Hassan, peace be upon him Public Library, Najaf Al-Ashraf, Iraq.

18-El-Kef, Abdullah (2014) The application of statistical processes in scientific research with the use of the . program Spss 1, i, Library of Law and Economics Riyadh.

19-Kaouane, Fares (2012) Algerian Historians and the Growth of Historical Consciousness (1830-1962) Contribution to Cultural and Intellectual History, Faculty of Humanities, Mentouri University of Constantine, unpublished MA thesis.

20-Dictionary of Psychology and Education (1984) The General Authority for Amaziah Press Affairs, Volume 1.

21-Fadli, Muhammad Rijal, et al. (2021) The effect of the Surugan method in learning history to increase historical understanding and historical awareness, International Journal of Evaluation and Research in Education (IJERE) Vol. (10), I)ssue (10).( 